\title{
SOliCiTUd DE ACCESO A LA INFORMACIÓN Y TUTELA DE LOS DATOS PERSONALES DE UN TERCERO
}

[Access to Information Request and Personal Data Protection of a Third Party]

\author{
Francisco Javier Sanz Salguero*
}

\begin{abstract}
RESUMEN
A partir de la entrada en vigencia de la Ley de transparencia, ha sido constante la tensión en la labor de conciliación entre el acceso a la información pública y la protección de los datos de carácter personal (particularmente, los datos nominativos de terceros). En este documento, explicamos cuál es el estado de la cuestión dentro de esa labor en el contexto jurídico chileno, abarcando su tratamiento doctrinal, legal y jurisprudencial, con énfasis en las decisiones del Consejo para la Transparencia.
\end{abstract}

\section{Palabras Clave}

Transparencia - Acceso a la información pública - Datos personales.

\section{ABstract}

Since the Transparency Act came into force, the tension in the conciliation task between the access to public information and the protection of personal data (particularly, of third-party nominative data) has been continuous. This document explains how things stand within this task is in the Chilean legal context, including its doctrinal, legal and jurisprudential treatment, focused on the decisions of the Counsel for Transparency.

\section{KEYWORDS}

Transparency - Access to public information - Personal Data.

RECIBIDO el 11 de septiembre y ACEPTADo el 9 de diciembre de 2013

* Candidato a doctor en Derecho por la Pontificia Universidad Católica de Valparaíso. Licenciado por Universidad Externado de Colombia. Dirección postal: Avenida Brasil 2950, Valparaíso, Chile. Dirección electrónica: fjsanzsalguero@hotmail.com.El autor agradece al Prof. Dr. Alan Bronfman Vargas, por los aportes realizados durante el desarrollo de este trabajo. 


\section{INTRODUCCIÓN}

Con casi una década de diferencia, los legisladores chilenos aprobaron la Ley $\mathrm{N}^{\circ} 19.628$ de 1999 , encargada de regular la protección de datos personales, y la Ley No 20.285 del 2008, encargada de normar el régimen de acceso a la información pública. Ambos cuerpos legales regulan la información, pero desde diversas aristas: el primero resguarda la información que concierne a personas naturales identificadas o identificables (es decir, los datos personales) buscando garantizar que sus titulares sean quienes decidan sobre su uso; entretanto, el ámbito del segundo es la información que obra en poder de los órganos del Estado (la que puede incluir datos de carácter personal) con la pretensión de favorecer su conocimiento por parte de los ciudadanos. La protección de los datos personales ampara la intimidad y la autodeterminación informativa; la transparencia administrativa favorece la probidad y potencia la participación ciudadana. Todos ellos son bienes jurídicos reconocidos por la Constitución y, por ende, potencialmente antagónicos, divergencia demostrada (entre otros factores) con el gran número de decisiones de amparo emitidas por el Consejo para la Transparencia desde su creación, y originadas dentro del trabajo de armonización entre dos derechos: el acceso a la información pública y la protección de los datos de carácter personal ${ }^{1}$.

La necesidad de superar el conflicto entre derechos, exige dar respuesta a diversas interrogantes: ¿Qué principio debe aplicarse cuando nos enfrentemos a esta intersección? ¿El deber de resguardar la confidencialidad de los datos personales o el derecho de las personas a acceder a la información pública? ¿A qué mecanismos debe acudirse para superar ésta tensión? ¿Cuál sería la solución institucional más adecuada para resolver el conflicto: la existencia de un solo organismo encargado de resolver ambos temas, o de entidades perfectamente diferenciadas? ¿Acaso éstas tensiones deben ser resueltas por los tribunales de justicia?

El esfuerzo asumido desde su creación por el organismo encargado de la

${ }^{1}$ El Consejo para la Transparencia ha debido ejercer la atribución consagrada en el artículo 33 letra m) de la "Ley de transparencia", aprobada por el artículo 1 de la Ley No 20.285 de 2008, consistente en velar por el debido cumplimiento de la Ley $\mathrm{N}^{\circ} 19.628$, sobre protección de datos de carácter personal por parte de los órganos de la Administración del Estado. A este respecto y dentro de su labor jurisprudencial, observamos por ejemplo que entre agosto de 2010 y marzo de 2011, el número de decisiones de fondo que aplicaron precisamente la citada Ley sobre protección de datos fue de 132, representando más del $27 \%$ de la totalidad de las providencias de fondo proferidas por este organismo. Ésta estadística confirma la importancia que ha tenido el trabajo de conciliación entre la transparencia y la tutela de los datos de carácter personal para el Consejo. Véase: Protección de datospersonales (Santiago, Consejo para la Transparencia 2011), p. 38. 
transparencia y la obligación de establecer los instrumentos que faciliten el cumplimiento de los objetivos generadores de la normativa sobre transparencia (mejorar sustancialmente el funcionamiento del Estado a partir de su escrutinio constante por parte de la ciudadanía, precaver la corrupción y terminar con el secretismo) confirma la necesidad de responder en la realidad jurídica chilena los interrogantes planteados.

Las anteriores preguntas también se han presentado en los ordenamientos jurídicos que han llegado a regular estas instituciones. Si bien es cierto cada Estado debe construir una solución a la medida de su realidad social y jurídica, es pertinente ver algunos ejemplos en el derecho comparado:

i) Para el caso español, Piñar Mañas considera imprescindible aclarar la relación existente entre transparencia y protección de datos, subrayando la importancia capital de la primera para el desarrollo de una sociedad abierta y democrática, y la necesidad de no considerar el respeto a la protección de datos como un obstáculo al derecho de acceso a la información. Lo anterior, sin olvidar que una de las excepciones que puede invocarse al ejercer el derecho de acceso, es la derivada de la protección de datos, o de la existencia de información o documentos que afecten a la intimidad de las personas. Igualmente, para Piñar Mañas ni la transparencia ni la protección de datos son absolutos, siendo preciso conseguir un equilibrio entre ambos derechos.

El mismo autor recuerda cómo el grupo de trabajo previsto en el artículo 29 de la Directiva $N^{\circ}$ 95/46/CE (Grupo de protección de las personas en lo que respecta al tratamiento de datos personales), en su Dictamen $\mathrm{N}^{\circ} 3 / 99$, relativo a información del sector público y protección de datos personales (WP 20), aprobado el 3 de mayo de 2003, estima que el "carácter público de un dato de carácter personal, resulte de una normativa o de la voluntad de la propia persona a la que alude el dato, no priva ipso facto y para siempre a dicha persona de la protección que le garantiza la ley en virtud de los principios fundamentales de defensa de la identidad humana"2; en sintonía con ésta afirmación, el mencionado Grupo de Trabajo plantea los aspectos a tener en cuenta a afecto de conciliar el respeto del derecho a la intimidad y a la protección de los datos personales de los ciudadanos, con el derecho a acceder a la información del sector público.

ii) En el caso uruguayo, Delpiazzo afirma que "siendo la persona un ser individual y a la vez social, confluyen en ella la perspectiva tutelar de lo íntimo y el afán de acceder cada vez a más información, especialmente aquella en poder de Administraciones públicas y que contiene muchas veces datos personales propios y ajenos". Así, este autor en aras de la adecuada ponde-

${ }^{2}$ Piñar MaÑas, José Luis, Seguridad, transparencia y protección de datos: El futuro de un necesario e incierto equilibrio (Madrid, Fundación Alternativas, 2009), p. 64. 
ración, estudia las dos visiones (visión desde la privacidad y visión desde el acceso) y los derechos fundamentales que involucran ${ }^{3}$.

\section{Protección de los datos PeRsonales y DeRecho de ACCeso}

\section{A LA INFORMACIÓN PÚBLICA: ¿DERECHOS FUNDAMENTALES CON RELEVANCIA EQUIVALENTE?}

El estudio de la relación entre la protección de los datos personales y el derecho de acceso a la información pública, plantea un interrogante inicial: ¿estos son derechos fundamentales con relevancia equivalente?

En primer lugar, y dentro del trabajo de respuesta a la pregunta sugerida, es necesario determinar cuál es la noción de d e rech o funda m e n t a l. Teniendo en cuenta la actual pluralidad de sentidos para la expresión d e r e chos fund a m e n t a le s ${ }^{4}$, una solución ante esa pluralidad sugiere distinguir entre un aspecto formal y un aspecto material del carácter fundamental de tales derechos. El aspecto formal del carácter fundamental se encontraría asociado a su constitucionalización lo que implicaría, en palabras de Gomes Canotilho: i) que los preceptos que consagran derechos fundamentales, en cuanto preceptos fundamentales, gozan de una posición de supremacía en el ordenamiento jurídico; ii) que en cuanto a preceptos constitucionales, se ven afectados por los requisitos especiales de la reforma constitucional; iii) que como preceptos que dan origen a normas vinculantes, constituyen exigencias materiales del ejercicio de las competencias de los órganos públicos.

El aspecto material del carácter fundamental alude a la naturaleza de ciertos derechos como elementos constitutivos del orden político, se encuentren

${ }^{3}$ Delpiazzo, Carlos E., A la búsqueda del equilibrio entre privacidad y acceso [visible en internet: http://www.fder.edu.uy/contenido/pdf/9jornadas_idi.pdf, consultado el 8 de enero del 2013].

${ }^{4} \mathrm{Al}$ respecto, se plantean tres alternativas para definir la expresión "derechos fundamentales": $i$ ) en un sentido general (y, de hecho, el más difundido) la citada expresión se usa para aludir aquellos derechos de la persona que han recibido consagración positiva, en particular, a nivel constitucional; $i$ ) otra postura, identifica estos derechos como aquellos de los que es titular el hombre, no por graciosa concesión de las normas positivas, sino con anterioridad e independientemente de ellas y por el mero hecho de ser hombre, tratándose entonces de aquellos atributos vinculados directamente a la dignidad humana y que constituyen un conjunto limitado en su extensión sólo a aquellos que son condición para la satisfacción de las necesidades inherentes a una vida digna; y iii) como tercera alternativa, se sugiere identificar estos "derechos fundamentales" como aquellos derechos subjetivos que corresponden universalmente a todos los seres humanos, al poseer el status de personas con capacidad de obrar, de ciudadanos. Véase: Aldunate Lizana, Eduardo, Derechos fundamentales, (Santiago, Legal Publishing, 2008), pp. 47 s. 
o no consagrados en el texto constitucional; en este orden de ideas, cuando estos derechos fundamentales en sentido material se encuentran insertos en el texto constitucional, a partir de ellos se puede construir una teoría de límites implícitos al poder constituyente derivado; al contrario, cuando estos no se encuentran consagrados en una carta política, la idea de derechos fundamentales en sentido material justifica la denominada cláu su la $\mathrm{a} b$ i e $\mathrm{r} \mathrm{t}$ a de los derechos fundamentales, haciendo referencia a la apertura de fuentes para considerar, como parte del ordenamiento constitucional, tales derechos aun cuando no incorporados en el texto de la constitución. Es pertinente aclarar que la noción de cláusula abierta no implica una habilitación ilimitada al intérprete u órgano de la jurisdicción constitucional, para revelar un catálogo de derechos fundamentales implícitos en un texto normativo: solamente derechos cuya materialidad fundamental sea demostrable, pueden poseer tal calidad'5.

En segundo lugar, concretamente en lo relativo a la protección de los datos de carácter personal, la tutela de este tipo de información es considerada como una derivación del derecho a la intimidad ${ }^{6}$; para la doctrina, ésta protección es un derecho de tercera generación ${ }^{7}$, dotado de autonomía ${ }^{8}$. No se trataría entonces del "puro derecho a ser dejado solo, en la formulación decimonónica del derecho a la intimidad ("the right to be let alone"), sino del derecho a la autodeterminación informativa, esto es, el derecho de las personas a controlar sus datos personales, incluso si éstos no se refieren a su intimidad"9. Para el caso chileno, durante el trabajo de consagración del derecho a la vida privada (dentro del proceso de redacción de la Carta Política de 1980 y la reforma constitucional del 2005) se discutió la adopción de expresiones como "intimidad" o "privacidad", estableciéndose finalmente el actual artículo $19 \mathrm{~N}^{\circ} 4^{\circ} \mathrm{CPol}$. que se reconoce expresamente el "respeto y protección a la vida privada y a la honra de la persona y su familia”" ${ }^{10}$. Ya a nivel

${ }^{5}$ Ibíd., p 49.

${ }^{6}$ Rajevic Mosler, Enrique, Protección de datos y transparencia en la Administración Pública chilena: Inevitable y deseable ponderación, ponencia dictada en el $26 \mathrm{de}$ noviembre del 2010 en el taller "Chile y la protección de datos personales" de la Corporación Expansiva, publicada en diciembre del 2010 por ella misma, p 4.

${ }^{7}$ Delpiazzo, Carlos E., cit. (n. 3), p. 2.

${ }^{8}$ Canales Gil, Álvaro, La protección de datos personales como derecho fundamental, en Anuario Derecho Informático, 4 (Montevideo, Fundación de Cultura Universitaria, 2004), pp. $264 \mathrm{~s}$.

${ }^{9}$ Rajevic Mosler, Enrique, cit. (n. 6), pp. 4 s.

${ }^{10}$ Sobre el particular y para tener en cuenta Anguita Ramírez, Pedro, La protección de datos personales y el derecho a la vida privada, régimen jurídico, jurisprudencia y derecho comparado (Santiago, Editorial Jurídica de Chile, 2007), pp. 119-133, quien analiza el proceso de redacción del actual artículo 19 numeral $4^{\circ}$ de la Constitución, in- 
normativo, la Ley No 19.628 aparece titulada como: Ley sobre protección de la vida privada, además de Ley sobre protección de datos de carácter personal.

En lo referente al derecho de acceso a la información pública, éste viene a ser reconocido en Chile por la Ley No 19.653 de 1999 sobre probidad administrativa, estatuto que además de consagrar como regla general la publicidad de los actos administrativos, restringió la reserva a un listado basado en cuatro causales que podía ser desarrollado por vía reglamentaria $\mathrm{y}$ admitiendo una impugnación en sede judicial ${ }^{11}$.

Sin embargo, un giro al respecto se presentó en septiembre del 2006 con la Sentencia de la Corte Interamericana de Derechos Humanos en el caso "Claude Reyes y otros contra Chile", la cual declaró que el sistema de acceso a la información chileno infringía el artículo 13 de la Convención Americana sobre Derechos Humanos o "Pacto de San José", pues éste garantizaba "el derecho que tiene toda persona a solicitar el acceso a la información bajo el control del Estado" (párrafo 77). De tal manera que, para la Corte, con base en el artículo 5 de la Carta Política chilena (norma que exige a los órganos del Estado respetar y promover los derechos esenciales que emanan de la naturaleza humana garantizados "por los tratados internacionales ratificados por Chile y que se encuentren vigentes", incluido el "Pacto de San José") éste derecho de acceso se habría incorporado en la Carta Fundamental ${ }^{12}$. Sin embargo, la cuestión sobre la posición constitucional de los derechos reconocidos por los tratados internacionales, ha sido un tema materia de controversia en Chile en el último tiempo, tal como lo recuerda Aldunate Lizana ${ }^{13}$. En este sentido, observamos dos posiciones al respecto: por un lado, un sector de la doctrina considera que a partir de la reforma introducida al señalado artículo $5 \mathrm{CPol} .{ }^{14}$, se había elevado a rango constitucional los tratados internacionales (ratificados y vigentes) en materia de derechos humanos (anotándose incluso una variante a esta opinión según la cual, lo que se había incorporado a la Constitución y a su jerarquía no eran los tratados, sino los derechos contenidos en ellos), opinión adoptada por autores como Pinochet Elorza, Jara Castro y Medina Quiroga ${ }^{15}$. Al contrario, otro sector estima inadmisible la tesis de elevación de jerarquía normativa de los tratados, a partir de la modificación del citado artículo 5 , siendo de esta opinión

cluyendo las razones de la proposición de expresiones como "intimidad” y "privacidad”, hasta llegar a la definitiva "vida privada".

${ }^{11}$ Artículo 14, Ley No 19.653 de 1999.

${ }^{12}$ Rajevic Mosler, Enrique, cit. (n. 6), p. 9.

${ }^{13}$ Aldunate Lizana, Eduardo, cit. (n. 4), pp. 338-345.

${ }^{14}$ Modificación introducida por la Ley No 18.825 de 1989 que reformó la Constitución.

${ }^{15}$ Aldunate Lizana, Eduardo, cit. (n. 4), p. 338. 
autores como Saenger Gianoni ${ }^{16}$, idea compartida incluso por el Tribunal Constitucional en su jurisprudencia ${ }^{17}$. Finalmente, llama la atención que el mismo Tribunal, en sintonía con lo dispuesto por la Corte Interamericana de Derechos Humanos, declaró mediante sentencia del nueve de agosto del 2007 el reconocimiento tácito en la Constitución del derecho de acceso a la información pública, estimando que "el derecho a acceder a las informaciones que obran en poder de los órganos del Estado forma parte de la libertad de expresión que, entre nosotros, se encuentra consagrada en el artículo $19 N^{\circ} 12$ de la Carta Fundamental, que asegura a toda persona "la libertad de emitir opinión y la de informar [...]", agregando la máxima instancia constitucional que la libertad de informar incluye "el derecho a recibir informaciones"18.

Realizada la exposición anterior, observamos la vigencia del interrogante propuesto, pregunta cuya respuesta solo será posible ejecutando un estudio sistemático de la materia. Así las cosas, para determinar si la protección de los datos personales y el derecho de acceso a la información pública son derechos fundamentales con relevancia equivalente, iacaso debemos otorgar al segundo el carácter de derecho fundamental en los términos propuestos por la Corte Interamericana de Derechos Humanos?, ¿el acceso a la información pública simplemente ya está reconocido tácitamente en el artículo 19 № 12 CPol., según lo estima la jurisprudencia del Tribunal Constitucional? La discusión queda abierta.

\section{Estado de la cuestión en el Derecho chileno}

La posibilidad de establecer concretamente hasta dónde el particular debe soportar el esfuerzo en aras del acceso a la información pública (limitándonos a una información puntual: los datos de carácter personal) dentro del marco de aplicación de la "Ley de transparencia", se encuentra restringida principalmente en la actual estructura jurídica nacional a los siguientes tópicos:

i) Al reconocimiento del deber del Estado de entregar la información.

ii) Al tratamiento de un tipo de información especialmente resguardada, representada por los datos personales, desde la óptica de la transparencia.

iii) A las decisiones de amparo del Consejo para la Transparencia y las sentencias proferidas por las altas instancias del poder judicial (por ejemplo, las Cortes de Apelaciones y el Tribunal Constitucional) en las cuales son tratados los enunciados datos personales.

\footnotetext{
${ }^{16}$ Ibíd., p 339.

17. Sentencia del Tribunal Constitucional, rol No 346/2002, de 8 de abril de 2002.

${ }^{18}$, Sentencia del Tribunal Constitucional, rol No 634/2006, de 9 de agosto de 2007, Considerando $9^{\circ}$.
} 
El estudio de los aspectos anteriores, nos permitirá identificar en la realidad jurídica interna dos temas concretos:

i) Cómo se estructura el deber del Estado de entregar la información (teniendo en cuenta las bases legales de este deber, las excepciones al mismo, y las características más importantes del organismo creado por la "Ley de transparencia" y encargado de velar por el cumplimiento de esta obligación).

ii) Cuál es el tratamiento de los derechos del particular cuya información se encuentra en poder del Estado (observando en este punto, el tratamiento de los datos personales en el ámbito legal y jurisprudencial desde la óptica de la transparencia).

Entonces a continuación, y para tener una noción del estado de la cuestión, estudiaremos los tópicos enunciados.

\section{Tratamiento del deber del Estado de entregar información}

La facultad del ciudadano de acceder a la información pública, representa el reconocimiento de dos condiciones esenciales para el desenvolvimiento sano de la democracia y el desarrollo del país: los principios de probidad y transparencia; estos se encuentran estrechamente ligados entre si ya que, de la aplicación exitosa del segundo, dependerá en gran medida la vigencia del primero.

La comprensión del anterior argumento, exige el conocimiento de tales garantías. Para comenzar, observamos que el Diccionario de la Real Academia Española de la Lengua identifica el término p robid a d con h o $\mathrm{n} \mathrm{radez}$ y define ésta, a su vez, como "rectitud de ánimo, integridad en el obrar", ya desde el punto de vista legal, el principio de probidad administrativa consiste en "observar una conducta funcionaria intachable y un desempeño bonesto y leal de la función o cargo, con preeminencia del interés general sobre elparticular", según lo estipula el artículo 54 inciso $2^{\circ}$ de la Ley No 18.575: Orgánica constitucional de bases generales de la Administración del Estado. Ahora bien, para permitir que éste principio se haga realidad, la Ley orgánica adopta diversas medidas: establece inhabilidades e incompatibilidades para los servidores públicos (artículos 56, 57 y 58) y describe conductas que contravienen especialmente el principio de la probidad administrativa (artículo 64). Además, estipula deberes positivos derivados de la probidad, como la necesidad de prestar ciertas declaraciones para acceder a cargos públicos, incluidas las declaraciones de intereses y de patrimonio de las altas autoridades.

En este orden de ideas, el mismo Diccionario afirma que algo es transparente cuando a través de él pueden verse los objetos claramente. En efecto, a consecuencia de los casos de corrupción en el sector público chileno ocurridos con posterioridad del retorno a la democracia, se fijaron normas con la pretensión de permitir a la ciudadanía conocer por qué, como actúa 
y que decisiones adopta la Administración del Estado, reconociéndose plenamente la importancia del principio de la transparencia en las actuaciones de sus funcionarios. Así, cualquier ciudadano podría evaluar y fiscalizar directamente el respeto al principio de probidad, participando de paso de la gestión pública. Por otra parte, la publicidad que permite la transparencia inhibe las conductas contrarias a la probidad, pues los servidores públicos no querrían verse expuestos a las posibles sanciones y a la censura social que generará la difusión de tales conductas.

Establecida entonces la naturaleza del vínculo entre dos garantías (probidad y transparencia) corresponde ilustrar cuales son las bases legales del deber del Estado de entregar la información, las excepciones a ese deber, y las características más importantes (funciones, naturaleza jurídica y atribuciones principales) del organismo creado por la "Ley de transparencia", encargado de velar por el cumplimiento de esta obligación: el Consejo para la Transparencia. A continuación, se identifican tales aspectos.

a) Fundamentos legales del deber del Estado de entregar infor mación. La "Ley de transparencia" se encargó de sistematizar en un solo cuerpo legal las normas sobre acceso a la información y transparencia activa, creando además un nuevo organismo autónomo, el Consejo para la Transparencia, responsable de fiscalizar la aplicación del principio de transparencia.

Se observa entonces, que la normativa identifica dos facetas en este deber de proporcionar información: en primer lugar tenemos la transparencia activa, que consiste en la acción positiva del Estado de poner información a disposición permanente del público sin mediar requerimiento formal, acudiendo para ello a herramientas tales como los sitios "web" que los servicios públicos mantienen o a las Oficinas de Información, Reclamos y Sugerencias (artículos 7, 8 y 9).

En segundo término (y tal como lo consagra el artículo 10 y siguientes de la Ley en estudio) destacamos la transparencia pasiva o derecho de acceso a la información en poder del Estado, garantía que implica la entrega de la información que no está sujeta al régimen anterior, por parte de la Administración Pública a los ciudadanos que la requieran, a través de los mecanismos especialmente dispuestos para ello (el mecanismo consiste en solicitar la información al propio organismo público).

Precisamente, como ya lo enunciamos en materia de acceso a la información en poder del Estado, la regla general en Chile es la publicidad de los actos, sus fundamentos y los procedimientos empleados al adoptarlos, siendo la excepción su reserva o secreto ${ }^{19}$. El artículo 21 de la "Ley de transparencia"

${ }^{19}$ Sobre este punto, la Corte Interamericana de Derechos Humanos ha enfatizado 
establece casos concretos en que concurren estas circunstancias ${ }^{20}$, algunas de las cuales abren campo a la aplicación de la Ley No 19.628 de 1999, encargada del tratamiento de los datos de carácter personal en registros o bancos de datos por organismos públicos o por particulares. En este contexto, nos interesa en especial lo anotado en el numeral $2^{\circ}$ del mencionado artículo 21 , el cual establece como causal de reserva o secreto para entregar la información, cuando su publicidad, comunicación o conocimiento afecte los derechos de las personas. La Ley puede estipular que estos últimos prevalezcan sobre la transparencia, ya que incluso la Constitución asegura a todas los individuos el respeto y protección de su vida privada (artículo $19 \mathrm{~N}^{\circ} 4^{\circ}$ ) y consagra que derechos como éste sean acatados y promovidos por los órganos públicos (artículo 5 inciso $2^{\circ}$ ). El precepto legal establece que la afectación de los derechos de las personas es una causal legítima de reserva o secreto, incluyendo particularmente en esta protección ${ }^{21}$ :

i) la información referida a la seguridad de las personas, lo que supondría, por ejemplo, que datos como la dirección personal no pueda ser entregada a terceros sin el consentimiento de su titular;

ii) la información referida a la salud de las personas, física y psíquica, lo que por ejemplo se aplicaría a las fichas o expedientes médicos o sanitarios;

iii) la información referida a la esfera de la vida privada de las personas ${ }^{22}$;

iv) la información referida a derechos de carácter comercial o económico de las personas. En este rubro, deben incluirse los antecedentes que manejan instituciones fiscalizadoras como las Superintendencias o el Servicio de Impuestos Internos, al igual otros que pueda conocer una institución pública

que la restricción de la publicidad sólo puede fundarse en motivos muy calificados, a efecto de no multiplicar las excepciones. Véase la sentencia de aquella Corte en el caso "Caso Claude Reyes y otros contra Chile", de 19 de septiembre de 2006, párrafos 88 a 91.

${ }^{20}$ En resumen, el artículo 21 de la "Ley de transparencia" establece como únicas causales de secreto o reserva, en cuya virtud se podrá denegar total o parcialmente el acceso a la información, cuando su publicidad, comunicación o conocimiento afecte: el debido cumplimiento de las funciones del órgano, los derechos de las personas, la seguridad de la nación y el interés nacional. Estas excepciones también incluyen los documentos, datos o informaciones que una ley de quórum calificado les otorgue el carácter de secretos o reservados

${ }^{21}$ Manual de transparencia y probidad de la Administración del Estado (Santiago, Ministerio Secretaría General de la Presidencia, Dirección Nacional del Servicio Civil, 2009), pp. 72 s.

${ }^{22}$ Sobre este punto, el artículo 30 inciso final de la Ley No 19.733 sobre libertades de opinión e información y ejercicio del periodismo, considera "como pertinentes a la esfera privada de las personas los hechos relativos a su vida sexual, conyugal, familiar o doméstica, salvo que ellos fueren constitutivos de delito". 
(por ejemplo, en el marco de una licitación) si se vinculan con asuntos de propiedad intelectual o industrial o de competitividad en el mercado.

Continuando con esta causal, existen otras leyes que establecen casos de reserva o secreto basados en los derechos de las personas. De estas, nos interesa en particular la Ley $N^{\circ} 19.628$, normativa que obliga a quienes trabajan en el tratamiento de datos personales (sea en organismos públicos o privados) a guardar secreto sobre los mismos, cuando provengan o hayan sido recolectados de fuentes no accesibles al público. En páginas posteriores, y dentro de esa labor para establecer hasta dónde el particular debe soportar el esfuerzo en facilitar el acceso a la información pública (limitándonos a los datos de carácter personal) repasaremos los aspectos más relevantes del texto legal enunciado.

b) El Consejo para la Transparencia. Esbozadas las bases legales al deber del Estado de entregar información, y las excepciones a ese deber, es pertinente anotar las características más importantes (funciones, naturaleza jurídica y atribuciones principales) del organismo creado por la "Ley de transparencia" y encargado de velar por el cumplimiento de esta obligación: el Consejo para la Transparencia.

Las funciones otorgadas por la señalada Ley a éste Consejo, son las de promover la transparencia de la función pública, fiscalizar el cumplimiento de las normas sobre transparencia y publicidad de la información de los órganos de la Administración del Estado y garantizar el derecho de acceso a la información (artículo 32). En cuanto a su naturaleza jurídica, se trata de una corporación autónoma de derecho público, con personalidad jurídica y patrimonio propio, que no depende de ningún Ministerio para preservar su independencia.

De entre las diversas atribuciones y funciones que la "Ley de transparencia” otorga al Consejo, todas ellas consignadas en su artículo 33, para efectos de nuestro estudio destacamos una: velar por el adecuado cumplimiento de la Ley $\mathrm{N}^{\circ} 19.628$, de protección de datos de carácter personal, por parte de los órganos de la Administración del Estado [artículo 33 letra m) ] ${ }^{23}$. Esta función

${ }^{23}$ Recordando cómo la primera parte del artículo 22 de la Ley No 19.628 establece que: "El Servicio Civil e Identificación llevará un registro de los bancos de datos personales a cargo de los organismos públicos", para el profesor JiJena LeIVA, Renato, Tratamiento de datos personales al interior de la Administración del Estado como restricción a la Ley 20.285 sobre Transparencia y acceso a la información de los Servicios Públicos, informe en Derecho elaborado a petición del Consejo para la Transparencia en diciembre del 2009, texto no publicado, p. 34, en lo que concerniente a la competencia del Consejo para la Transparencia, este organismo debiera instruir a los servicios públicos para que den cumplimiento a la obligación de registro, en los términos establecidos por el Decreto Supremo $\mathrm{N}^{\circ} 779$ que reglamenta este artículo 22. De tal manera que, el Consejo 
otorga al Consejo para la Transparencia la facultad de proponer b u e n a s prácticas complementarias de las normas obligatorias contenidas en la Ley $\mathrm{N}^{\circ} 19.628$ (buenas prácticas que observan el carácter de r e c o m e n d a c i o n e s) cuyo objeto es facilitar la comprensión y orientar para un mejor cumplimiento de las obligaciones que el señalado cuerpo legal impone a los órganos de la Administración del Estado, en materia de protección de datos personales ${ }^{24}$. Sin embargo, actualmente el Consejo no posee un rol fiscalizador en el cumplimiento de las normas sobre tratamiento y protección de datos nominativos. Anotando que cursa en el Congreso de Chile, un proyecto de ley que pretende otorgar al Consejo para la Transparencia la facultad de fiscalizar el cumplimiento de las normas sobre tratamiento y protección de datos personales (proyecto que estudiaremos en páginas posteriores), dentro de algunas experiencias en el ámbito del derecho comparado, observamos la tendencia al establecimiento de organismos que asumen la doble funcionalidad de promover el acceso público a la información oficial y proteger la información personal. A este respecto, tenemos los casos "México con el Instituto Federal de Acceso a la Información y Protección de Datos", y "Reino Unido con la Oficina del Comisionado de Información” (Information Commissioner's Office).

Hasta este punto, hemos ilustrado cómo se estructura de manera general en el derecho chileno, el deber del Estado de entregar la información. A continuación, y dentro de esa tentativa por armonizar el derecho de acceso y la protección de los datos de naturaleza personal desarrollado por la doctrina y la jurisprudencia nacional, expondremos los dos últimos tópicos planteados, a saber: el tratamiento de un tipo de información especialmente resguardada, representada por los datos pe r so nales, desde la óptica de la transparencia; y el contenido de las decisiones de amparo del Consejo para la Transparencia y algunas sentencias proferidas por las altas instancias del poder judicial, referidas a datos personales, desde el punto de vista de la transparencia.

\section{Tratamiento de los derechos del particular cuya información se encuentra en poder del Estado.}

a) Solicitud de acceso a la información pública y los datos personales del tercero: tratamiento legal. Al estar en presencia de la solicitud de entrega de información pública que puede afectar los derechos

no puede asumir como propias las competencias que la ley No 19.628 asigna al Registro Civil.

${ }^{24}$ Recomendaciones del Consejo para la Transparencia sobre protección de datos personales por parte de los órganos de la Administración de Estado, p. 2, publicadas en el Diario Oficial el 14 de septiembre del 2011. 
de un tercero, debemos considerar un segmento especialmente protegido a nivel normativo, y cuya divulgación solo será posible en situaciones limitadas. Esta información estaría conformada por los datos personales, es decir, aquella concerniente a una persona física identificada o identificable, sea que se trate de información numérica, alfabética, gráfica, fotográfica, acústica o de cualquier otro tipo $0^{25} \mathrm{o}$, en otras palabras, aquellos que nominada e individualmente permiten determinar con precisión los antecedentes personales de los ciudadanos, como por ejemplo el rol único tributario, nombre, dirección, comuna, teléfono, entre otros ${ }^{26}$. En relación con lo explicado, se entiende por identificable a toda persona cuya identidad puede determinarse, directa o indirectamente, por ejemplo, mediante un número de identificación o uno o varios elementos específicos característicos de su identidad física, fisiológica, psíquica, económica, cultural o social (verbi gratia: rol único tributario, número de cuenta corriente bancaria, etc.); en este orden de ideas, no se consideraría identificable si es necesario realizar actividades desproporcionadas o en plazos excesivos para lograr la identificación de una persona ${ }^{27}$.

Dentro de la anterior categoría de información, tenemos un grupo de datos relativos al fuero interno de los individuos y de escaso tratamiento público, representado por los datos sensibles. En el ámbito del derecho comparado, y principalmente a partir de la Directiva $N^{\circ}$ 95/46/CE del Parlamento Europeo y del Consejo de Europa, estos datos sensibles tanto en el texto de la Directiva, al igual que en algunos ordenamientos latinoamericanos (incluido el chileno) son objeto de enumeración taxativa, abarcándose conceptos como el origen étnico o racial, el domicilio, el patrimonio, el número telefónico, la ideología o las preferencias sexuales ${ }^{28}$.

Los datos de carácter personal, también incluyen información relativa al historial laboral, educativo, judicial, la identidad digital, entre otras materias. Recientemente, legislaciones como la italiana (concretamente en el artículo 4 del Codice in materia di protezione dei dati personali $\left.{ }^{29}\right)$ identifican los datos personales a nivel general, y establecen algunas de sus manifestaciones a saber: datos identificatorios (los cuales permiten la identificación directa

${ }^{25}$ Ibíd.

${ }^{26}$ Jijena Leiva, Renato, cit. (n. 23), p. 12.

${ }^{27}$ Recomendaciones del Consejo para la Transparencia, cit. (n. 24).

${ }^{28}$ Greg orio, Carlos, Los nombres de las partes en los documentos judiciales: vías de acceso a la información, publicidad, y protección de la intimidad (Buenos Aires, Instituto de Investigaciones para la Justicia, 2005), pp. $5 \mathrm{~s}$.

${ }^{29}$ Esta normativa fue publicada en la Gazzetta Ufficiale, el 29 de julio del año 2003 [visible en internet:http://www.camera.it/parlam/leggi/deleghe/testi/03196dl.htm, consultado el 15 de marzo del 2010]. 
del interesado); datos sensibles (objeto de una precisa enumeración) y datos judiciales (datos fundamentalmente de carácter penal).

La protección de los datos personales, es una garantía de resguardo $\mathrm{y}$ control de la propia información, contenida en bases de datos u otros sistemas, lo cual permite controlar su exactitud, corregirla, eliminarla y, en definitiva, disponer de ella. Hoy en día, estas bases de datos están informatizadas y disponibles para aquellos elementos del conglomerado social que estén dispuestos y puedan pagar por ellas, y por tanto existe la posibilidad de cruzar información y de tomar decisiones en base a esta, circunstancia que puede eventualmente afectar la vida de las personas. Tradicionalmente, se ha vinculado al derecho constitucional de respeto y protección a la vida privada, contenido en el artículo $19 \mathrm{~N}^{\circ} 4^{\circ} \mathrm{CPol} .^{30}$.

En este punto, y para efectos de nuestro análisis, es pertinente observar el tratamiento otorgado a los datos personales, tanto en la Ley No 19.628 sobre protección de la vida privada, como en la "Ley de transparencia". A continuación, desarrollaremos este trabajo.

b) Tratamiento otorgado a los datos personales en la Ley $\mathrm{N}^{\circ}$ 19.628 sobre protección de la vida privada. Como introducción a este tema, pensamos que el conocimiento de los aspectos más relevantes de la Ley No 19.628, es esencial para comprender el estado de la cuestión en la relación entre el derecho de acceso a la información pública y la protección de los datos de carácter personal. De tal manera que, en esta parte del documento, repasaremos aspectos puntuales referidos al contenido de la norma en estudio, como su ámbito de aplicación, los sujetos regulados, las situaciones en las que no se requiere autorización para el tratamiento de datos que provengan o se recolecten de fuentes accesibles al público y los derechos de los titulares de los datos de carácter personal.

Igualmente, y dada la insuficiencia detectada en la aplicación de la Ley No 19.628 (que se resume en que esta sólo regula el tratamiento de datos, y no el derecho de los titulares a controlar los mismos) repasaremos los contenidos de un proyecto de ley que cursa actualmente en el Congreso (Boletín No 6120-07) y que constituye, hasta la fecha, la iniciativa más importante en aras de una mejor protección de los datos nominativos de personas naturales y jurídicas ${ }^{31}$, observando en este punto sus fundamentos, objetivos

\footnotetext{
${ }^{30}$ Recordemos que el artículo $19 \mathrm{~N}^{\circ} 4 \mathrm{CPol}$., asegura a todas las personas "El respeto y protección a la vida privada y a la honra de la persona y su familia".

${ }^{31}$ Tan relevante es la propuesta de reforma, que el Consejo para la Transparencia contrató con la Universidad de Chile un estudio a efecto de investigar las implicancias organizacionales y de recursos que, eventualmente, representaría la entrada en funcionamiento de las nuevas competencias en materia de datos personales para la institución, estudio cuyos resultados fueron publicados en mayo del año 2010. Véase: Diseño
} 
y, en especial, el rol que la propuesta legislativa otorga al C o n s e jo pa r a la Transparencia y Protección de Datos Personales (incluyendo en este acápite las competencias atribuidas a este organismo de control y el análisis y recomendaciones que ya se han formulado en relación con estas nuevas competencias).

i) En segundo lugar, y en lo relativo al ámbito de aplicación de la Ley $\mathrm{N}^{\circ} 19.628$, esta se encarga del tratamiento de los datos de carácter personal en registros o bancos de datos por organismos públicos o por particulares (siendo de interés para efectos del estudio aquí desarrollado, lo referido a las bases de datos en organismos públicos) definiendo los datos personales como aquellos relativos a cualquier información concerniente a personas naturales (quedando así excluida de la protección de la normativa las personas jurídicas) identificadas o identificables [artículo $2^{\circ}$ letra f) $]^{32}$.

A su vez, el estatuto legal reconoce los denominados d a t o s se n sibles, comprensivos de informaciones relativas al fuero interno de los sujetos y de limitado tratamiento público, como aquel grupo de datos personales que se refieren a las características físicas o morales de las personas, o a hechos o circunstancias de su vida privada o intimidad, tales como los hábitos personales, el origen racial, las ideologías y opiniones políticas, las creencias o convicciones religiosas, los estados de salud físicos o psíquicos y la vida sexual [artículo 2, letra g)]. En concordancia con lo anterior, la norma proscribe el tratamiento de estos datos sensibles, salvo que el régimen legal lo autorice, exista consentimiento del titular o se trate de datos necesarios para la determinación u otorgamiento de beneficios de salud que correspondan a sus titulares (artículo 10) ${ }^{33}$.

La Ley en estudio, además de definir el concepto de dato personal

de un modelo organizacional del Consejo para la Transparencia en su nueva función de protección de datospersonales (Santiago, Centro de Sistemas Públicos, Departamento de Ingeniería Industrial de la Universidad de Chile, 2010), p. 4.

${ }^{32}$ Anotando que la Ley no excluye ningún tipo de base o registro de datos personales, quedarían sujetos a dicha norma incluso los que elaboran personas naturales en el ejercicio de sus actividades personales o domésticas. La legislación europea en esta materia, exceptúa de la aplicación de las leyes de datos este tipo de bases, dada la dificultad de fiscalizarlas y el escaso riesgo potencial a los derechos fundamentales de los ciudadanos. Véase: Anguita Ramírez, Pedro, cit. (n. 10), pp. 291 s.

${ }^{33}$ En efecto, los datos relativos a la salud de las personas, podrían ser tratados en aquellos casos en que los pacientes o enfermos lo consientan o los datos personales sean necesarios para la identificación u otorgamiento de beneficios de salud; lo anterior, en atención a la importancia para los profesionales de esta área en la prevención y diagnóstico adecuado de sus pacientes, incluso sin la autorización de estos últimos en los casos en que se encuentren jurídicamente imposibilitados para dar su consentimiento: Ibíd., p. 302. 
propiamente dicho, y de dato personal sensible distingue otras categorías como el dato estadístico (aquel que en su origen, o como consecuencia de su tratamiento, no puede ser asociado a un titular identificado o identificable) y el dato caduco (no verdadero, no pertinente o no necesario).

ii) Continuando con la exposición, respecto a los su j e t os r e gulad os por la Ley $\mathrm{N}^{\circ} 19.628$ tenemos, en primer término, al responsable de un registro,base o banco de datos (que puedeser una entidad particular natural o jurídica, o un servicio público), responsable que realiza el tratamiento de ellos; en segundo término, a la p e r s o n a natural titular de los datos; yen tercer término, al Servicio del Registro Civil y de Identificación, al cual la normativa en comento atribuye la labor de creación de un registro que incluya todos los bancos de datos personales en poder de organismos públicos, estipulando además el carácter público de dicho registro, y el fundamento jurídico, finalidad, tipos de datos almacenados y descripción del ámbito de personas que comprende, respecto de cada uno de los bancos de datos (artículo 22); sobre esta temática, y en aras de la efectiva protección de los datos personales, el legislador debería proponer un registro similar aplicable a bancos de bases de datos administradas por particulares.

iii) Siguiendo con el estudio de la Ley $N^{\circ} 19.628$, se sugiere un interrogante: ¿cuándo es posible el tratamiento de los datos pers o n a les? Sobre este particular, el señalado Estatuto limita el tratamiento de los datos personales a dos eventos: cuando esta u otra ley lo autorice, o cuando el titular lo consienta expresamente, regulando además el trámite de autorización. En la medida que un particular permita o una norma legal establezca que ciertos datos o antecedentes personales sean susceptibles de conocerse, éstos pasarán a formar parte de una esfera social. Excepcionalmente, el tratamiento es posible sin que sea necesaria la autorización del titular, cuando estos "provengan o se recolecten de fuentes accesibles al público" (artículo $4^{\circ}$ ); igualmente, y al tenor del artículo 20 de la Ley en estudio, se establece que dicho tratamiento "sólo podrá efectuarse respecto de las materias de su competencia y con sujeción a las reglas precedentes", condiciones en las cuales "no necesitará el consentimiento del titular". Así, en la práctica la regla general es la competencia del órgano de naturaleza pública, no exigiéndose la autorización del titular, privilegiándose de parte del legislador las funciones fiscalizadoras o de administración del Estado por sobre la vida privada de las personas.

En el evento en que el tratamiento de los datos personales sea consecuencia de una autorización legal (básicamente la Ley № 19.628 en sus artículos 2, 4 y 20, los instructivos presidenciales de Gobierno Electrónico, las leyes orgánicas de cada servicio, las normas especiales, y la Ley de bases generales 
de la Administración del Estado), esta autorización vendría a remplazar la voluntad o el consentimiento de los ciudadanos. A este respecto, Jijena Leiva opina que no existe fundamento jurídico para entender que lo dispuesto en los artículos 5 y 10 de la "Ley de transparencia", constituye una de aquellas autorizaciones legales para tratar los datos personales con prescindencia de la voluntad de su titular, a que alude la regla general del artículo 4 de la Ley No 19.628. En consecuencia y según esta opinión, solicitados por un tercero sin expresión de causa o motivo y denegados de entregarse por un órgano del Estado, en sede del amparo al derecho de acceso del artículo 24 de la "Ley de transparencia”, el Consejo para la Transparencia debería abstenerse de fallar ordenando su entrega, cesión o comunicación ${ }^{34}$.

En lo relativo al tratamiento de los datos personales en registros o bancos de datos, la legislación chilena hace aplicable en esta materia sus disposiciones tanto a los registros llevados por organismo privados como públicos (subsistiendo eso si, diferencias en el tratamiento normativo entre unos y otros $^{35}$ ). Sobre este particular, el Consejo para la Transparencia enumera como ejemplos de registro o bancos de datos los registros de una institución (que pueden tener un carácter automatizado o no), los de datos de clientes,

${ }^{34}$ Jijena Leiva, Renato, cit. (n. 23), pp. 38 s.

${ }^{35}$ Como consecuencia de los avances en materia informática, se ha interrogado sobre el tratamiento de los datos personales almacenados en bases de datos de particulares; en este contexto, surgen diversos interrogantes: ¿qué ocurre con las opiniones vertidas en las r ed e s s o c i a le s ? ¿Cuál es el grado de protección para sus titulares, respecto de los datos personales recolectados en estos medio de comunicación social? En respuesta a las anteriores preguntas, en el ámbito normativo actual el tratamiento de los datos de carácter personal almacenados en bancos de datos de particulares es perfectamente posible, e incluso relativamente fácil. precisamente, si bien es cierto con base en el artículo 4 de la Ley $\mathrm{N}^{\circ} 19.628$, el tratamiento de los datos personales requiere la autorización por escrito del titular de los mismos, el propio artículo 4 establece que "no requiere autorización el tratamiento de datos personales que provengan o que se recolecten de fuentes accesibles al público, cuando sean de carácter económico, financiero, bancario o comercial" entre otros. Ahora bien, según el artículo $2^{\circ}$ letra i) de la misma Ley, se definen como fuentes accesibles al público: "los registros orecopilaciones de datos personales públicos o privados, de acceso no restringido o reservado a los solicitantes". Por tanto, y aplicando las definiciones y excepciones de la normativa chilena vigente, la redes sociales, y en general la información inserta en "internet", es considerada una información accesible al público, por lo que el acceso a la información obtenida por esta vía no es ilegal, siendo viable el tratamiento de los datos obtenidos por estos medios. Por último, y con el objeto de aclarar y complementar el concepto defuentes accesibles al público, actualmente cursa en el Congreso de Chile un Proyecto de Ley (Boletin No 6120-07 que exponemos en páginas posteriores) que pretende incluir entre estas fuentes los medios de comunicación social, adaptando el modelo español sobre la materia. 
los de datos de beneficiarios de subsidios, los de proveedores, un documento o tabla en "Excel" en el que se incluyan distintos nombres y direcciones de participantes de un evento, un conjunto de currículos en forma digital insertos en una carpeta catalogada por nombre, etc. ${ }^{36}$.

iv) Estrechamente ligado al interrogante anterior (es decir, cuándo es posible el tratamiento de los datos personales), es pertinente comentar en que situacionesno se requiere autorización para el tratamiento de datos por provenir o ser recolectados de fuentes accesibles al público. Sobre este punto en particular, los incisos $5^{\circ}$ y $6^{\circ}$ del artículo 4 de la Ley $N^{\circ} 19.628$, establecen diversas excepciones en relación a la autorización del titular requerida para el tratamiento de los datos. En efecto, la norma estipula que en determinados casos no requiere autorización el tratamiento de datos personales que provengan o que se recolecten de fuentes accesibles al público, estipulándose en concreto las siguientes situaciones de excepción: primero, cuando los datos personales sean de carácter económico, financiero, bancario o comercial, incluyendo en esta categoría los datos patrimoniales negativos, es decir, los referidos a insolvencia, mora y protestos, en concordancia con lo estipulado en los artículos 17, 18 y 19 de la Ley No 19.628; segundo, cuando los datos personales se contengan en listados relativos a una categoría de personas que se limiten a indicar antecedentes, tales como la pertenencia del individuo a ese grupo, su profesión o actividad, sus títulos educativos, dirección o fecha de nacimiento, observando que la expresión tales como demuestra el carácter de ejemplo de la señalada enumeración y, tercero, cuando los datos personales sean necesarios para comunicaciones comerciales de respuesta directa o comercialización o venta directa de bienes o servicios, excepción que en últimas legaliza, con mínimas limitaciones, el "marketing" directo.

En este contexto, y partiendo de la base, según la cual el artículo 2 letra i) de la Ley No 19.628 define "las fuentes accesibles alpúblico, como los registros o recopilaciones de datos personales públicos o privados, de acceso no restringido o reservado a los solicitantes", es pertinente establecer si las bases o bancos de datos personales o nominativos que mantienen los servicios públicos deben ser consideradas legalmente como fuentes de acceso público o como fuentes de acceso reservado o secreto. Para el profesor Jijena Leiva la respuesta a este interrogante sólo puede determinarse considerando la especial naturaleza del dato personal tratado, anotando que por regla general los sistemas de tratamiento de datos personales del sector público, no deben ser considerados fuentes accesibles al público o fuentes públicas de información nominativa,

\footnotetext{
${ }^{36}$ Recomendaciones del Consejo para la Transparencia, cit. (n. 24)..
} 
pese a la amplitud de la definición legal del señalado artículo $2^{37}$. Precisamente, la ambigüedad en esta definición de fuente accesible al público es criticada por Anguita Ramírez, quien considera esta descripción como la más desafortunada de la Ley $\mathrm{N}^{\circ} 19.628$, en comparación con otras normas similares, como por ejemplo el artículo 3 letra j) de la Ley orgánica de protección de datos de carácter personal de España ${ }^{38}$. Esta norma en particular define fuentes accesibles al público, como "aquellos ficheros cuya consulta puede ser realizada por cualquier persona, no impedida por una norma limitativa, o sin más exigencia que, en su caso, el abono de una contraprestación", estableciendo además taxativamente que: "tienen la consideración de fuentes de acceso público, exclusivamente, el censo promocional, los repertorios telefónicos en los términos previstos por su normativa especifica y las listas de personas pertenecientes a grupos de profesionales que contengan únicamente los datos de nombre, titulo, profesión, actividad, grado académico, dirección e indicación de su pertenencia al grupo". Finaliza el artículo comentando que "tienen el carácter de fuentes de acceso público, los Diarios y Boletines oficiales y los medios de comunicación".

v) Continuando con el repaso de la Ley No 19.628 , otro aspecto a observareseltratamiento de los derechos de los titulares de datos personales. En efecto, la normativa analizada concede a los titulares de datos nominativos los derechos de acceso, rectificación, cancelación y bloqueo, al igual que la irrenunciabilidad de los mismos, y garantiza el ejercicio de estos derechos reconociendo la acción, la autoridad competente y las consecuencias frente al acogimiento de la reclamación. En cuanto a las excepciones a las reglas generales de la Ley $N^{\circ} 19.628$, es pertinente examinar lo enunciado en su artículo 15 , norma que establece la imposibilidad de solicitar información, modificación, cancelación o bloqueo de datos personales, "cuando ello impida o entorpezca el debido cumplimiento de las funciones fiscalizadoras del organismo público requerido, o afecte la reserva o secreto establecidos en disposiciones legales o reglamentarias, la seguridad de la Nación o el interés nacional", y que prohíbe además la solicitud de "modificación, cancelación o bloqueo de datos personales almacenados por mandato legal, fuera de los casos contemplados en la ley respectiva". Anotamos que, al comparar este tratamiento excepcional, con las causales de reserva y secreto para acceder a información insertas en la "Ley de transparencia", el carácter genérico tanto de uno como de otro régimen podría ser utilizado por las autoridades públicas (por ejemplo, acudiendo a la interpretación extensiva de dichas causales) para no prestar la oportuna colaboración al ciudadano ante requerimientos de información.

${ }^{37}$ Jjena Leiva, Renato, cit. (n. 23), p. 28.

${ }^{38}$ Anguita Ramírez, Pedro, cit. (n. 10), pp. 295 s. 
vi) Para concluir el análisis de la Ley No 19.628, comentaremos la mo dificación más importante propuesta a la misma, concretamente el Boletín No 6120-07, centrándonos en sus fundamentos y objetivos y el rol que esta iniciativa legislativa otorga al nuevo $C$ on se jo pa ra la Transparencia y Protección de Datos Personales.

En cuanto a losfundamentos y objetivos del Boletin $\mathrm{N}^{\circ}$ 6120 - 07, reiterando que la Ley No 19.628 regula el tratamiento de datos y no el derecho de los titulares a controlar los mismos, esta premisa es la que se recoge en los fundamentos del señalado proyecto (el que se tramita actualmente en el Congreso) y que constituye, hasta la fecha, la iniciativa más importante en aras de la protección de los datos nominativos de personas naturales y jurídicas. Las razones que sustentan el cambio legislativo propuesto incluyen el carácter insuficiente de la regulación vigente (manifestado en la inexistencia de un registro de responsables privados de bases de datos y de un órgano fiscalizador autónomo; en la no prohibición de la transferencia internacional de datos personales a países carentes de un adecuado sistema de protección; y la no protección a las personas jurídicas, entre otros factores), la ausencia de una auténtica autoridad de control y la necesidad de adaptarse a estándares internacionales. Igualmente, la iniciativa tiene por objeto modificar la "Ley de transparencia", buscando (tal como lo expresa el proyecto en su "Descripción de la Propuesta") "[...] dar una eficaz respuesta a las exigencias de protección, ya que, por una parte, se mejoran los estándares de protección y resguardo de los derechos de los titulares de datos personales y, por otra, se confieren las competencias y herramientas necesarias a una autoridad autónoma para velar por el adecuado cumplimiento de las normas sobre protección de datos". En sintonía con lo enunciado, la propuesta de reforma tiene como objetivos generales el adecuar la legislación a estándares internacionales ${ }^{39}$, establecer un control efectivo y real de las personas sobre sus

${ }^{39}$ En materia de protección de datos, se han establecido internacionalmente determinados estándares, siendo de especial interés la Directiva Europea $N^{\circ}$ 46/95/CE, la cual señala que, frente a transmisiones internacionales de datos personales, el país receptor debe tener un nivel de protección adecuado en la materia. Esta Directiva, además de garantizar el principio de la libre circulación de los datos entre los Estados miembros, pretende garantizar el derecho a la intimidad en el tratamiento de los datos personales de las personas físicas. En concordancia con lo anterior, la expresión "protección adecuada”, genera a los terceros países las obligaciones de resguardar el conjunto de principios básicos de protección de datos contenido en la Directiva Europea, y de garantizar dichos principios de una manera efectiva. Así las cosas, no sería suficiente que la sola legislación plasme estos principios, siendo necesario el establecimiento de los medios idóneos para el ejercicio de tales derechos, como por ejemplo, la existencia un órgano de control responsable de la protección de datos autónomo e independiente, con un campo de aplicación público y privado y con facultades de fiscalización y sancio- 
datos ${ }^{40}$, y otorgar facultades al Consejo para la Transparencia (estableciendo así una autoridad de control) para fiscalizar el cumplimiento de las normas sobre tratamiento y protección de datos, conocer de las reclamaciones de particulares relacionadas con el ejercicio de sus derechos y llevar el registro de las bases de datos, públicas y privadas.

Un punto de especial interés, consiste en determinar si la función de protección de datos personales y la de acceso a información deben estar radicadas en una misma institución. Precisamente la propuesta legislativa analizada concede al Consejo para la Transparencia el carácter de autoridad de control y, en concordancia con las nuevas atribuciones, el nombre de Consejo para la Transparencia y Protección de Datos Personales. Si bien es cierto la sola lectura del proyecto de ley no es suficiente para responder al interrogante planteado, a efecto de coadyuvar con la respuesta a esta pregunta observaremos, a continuación, cuales son las funciones atribuidas por dicho proyecto al organismo encargado de velar por la protección de datos personales y el acceso a información (y el análisis y recomendaciones que ya se han formulado en relación con estas nuevas competencias $)^{41}$.

En este contexto, una primera función otorgada al Consejo es la de mantener un Registro Único Nacional de las Bases de Datos, sean estas de origen público o privado (artículo 33 bis letra a) de la "Ley de transparencia"). Entre otros aspectos, esta norma autoriza al Consejo a establecer la simplificación u omisión del registro, "cuando se tratare de categorias de tratamientos que no afecten a los derechos y libertades de los interesados, además de otros motivos legales". Sobre el particular se ha considerado que la obligación universal

nadoras; la presencia de un catálogo de infracciones y sanciones disuasivas, acompañadas por medidas de seguridad efectivas; la construcción de acciones administrativas y/o judiciales; y la disposición de sistemas de responsabilidad y reparación para los afectados. Véase: Estrategias emergentes para el desarrollo de la protección de datos en Chile del Consejo para la Transparencia [visible en Internet: http://www.consejotransparencia. cl/prontus_consejo/site/artic/20091214/pags/20091214173541.html, consultado el diez de abril del 2010].

${ }^{40}$ Según lo propuesto, el inciso $2^{\circ}$ artículo 1 de la Ley 19.628 quedaría así: “Toda persona tiene derecho a controlar la información que le concierne, de modo de obtener un adecuado resguardo a sus derechos fundamentales, sin que ello obstaculice innecesariamente el libre flujo de los datos personales"; esta norma determina entonces que la ley no absolutiza la protección de los datos personales, lo cual debería reflejarse en la institucionalidad y la organización. Así las cosas, ya sea que en Chile se integre la función de protección de datos personales y la de acceso a información en instituciones diferenciadas o una sola, el organismo encargado de tutelar los datos nominativos deberá hacer un trabajo de equilibrio entre ambos bienes jurídicos.

${ }^{41}$ Diseño de un modelo organizacional, cit. (n. 31) pp. 115-128. 
del registro puede generar un exceso de costo, recomendándose al Consejo acotar la obligación de registro y sugiriéndose que en el proyecto de ley se autoricen explícitamente otros motivos para permitir la omisión del registro por razones operativas.

Una segunda competencia que entrega el proyecto, es la de fiscalizar el cumplimiento de las disposiciones sobre tratamiento de datos personales, lo que permite al Consejo solicitar, en cualquier momento, del responsable del respectivo registro o banco de datos, la información que estime pertinente "artículo 33 bis letra b) "Ley de transparencia"]. Para lograr el éxito en esta labor, sería pertinente generar relaciones de coordinación con Carabineros a efecto de poder utilizar su apoyo en las fiscalizaciones forzadas, y generar mecanismos operativos específicos que faciliten esa colaboración.

Como tercera función otorgada al Consejo, tenemos la facultad de inspeccionar los registros o bancos de datos personales con el objeto de verificar el cumplimiento de las obligaciones que establece la ley (artículo 33 bis letra b) de la "Ley de transparencia"). Esta labor de fiscalización, se encuentra estrechamente ligada con lo estipulado en el inciso $4^{\circ}$ artículo 11 modificado de la Ley No 19.628, norma que establece: "Se considerará indebido el registro de datos de carácter personal en registros o bancos de datos que no den cumplimiento a las exigencias que determine el reglamento a que se refiere el presente articulo". Sobre el alcance de esta última norma, surgen dos preguntas: ¿el Consejo puede ordenar la cancelación de las bases de datos cuando se cumplan las exigencias?; en un mismo sentido, ¿qué medidas de fuerza se pueden adoptar para lograr el cumplimiento?

Una cuarta competencia que otorga el proyecto al Consejo, es la facultad de requerir la inscripción de los bancos de datos que no estén registrados en el Registro Único Nacional [artículo 33 bis letra c) de la "Ley de transparencia"]. El logro efectivo de esta labor, depende de la capacidad de establecer que organismos o personas no están en el registro. Al respecto se sugiere una colaboración con la Secretaria de Impuestos Internos, a fin de contar con un directorio que permita el cruce de información.

La quinta competencia que el proyecto de ley entrega, es la de dictar instrucciones de carácter general o particular respecto de las condiciones de legitimidad de un tratamiento de datos (artículo 33 bis letra d) de la "Ley de transparencia"]. Sobre el particular, se recomienda que esta potestad legal se desarrolle de manera mancomunada con las empresas, en un proceso abierto de diseño de normas. Lo anterior, con el doble propósito de ganar la confianza de las organizaciones y personas reguladas, y generar una mejor normativa.

Finalmente, otras atribuciones que la propuesta legislativa concede al Consejo para la Transparencia incluyen, en primer lugar, la potestad de conocer de las reclamaciones de particulares relacionadas con el ejercicio de 
sus derechos [artículo 33 bis letra e) de la "Ley de transparencia"]; sobre este proceso de reclamo, se recomienda incorporar en el diseño una solución alternativa (por ejemplo una conciliación) en aras de evitar, en lo posible, el desarrollo de un proceso estructurado contencioso, con alegaciones, pruebas y plazos. En segundo lugar, la facultad de sancionar a los responsables de los bancos de datos que infrinjan las normas sobre tratamiento y protección de datos personales [artículo 33 bis letra f) de la "Ley de transparencia"]; en relación a esta potestad sancionatoria, el nuevo artículo 26 de la Ley N$^{\circ}$ 19.628 determina el procedimiento administrativo para la aplicación de las sanciones previstas en la ley (en este caso, proyecto de ley). En tercer lugar, la facultad de requerir a los responsables y encargados de los tratamientos, previa audiencia de éstos, la adopción de las medidas necesarias para la adecuación del tratamiento de datos a las disposiciones de la ley y, en su caso, ordenar la cesación de los tratamientos y cancelación del registro [artículo 33 bis letra g) de la "Ley de transparencia"]; sobre el alcance de esta disposición, surge la pregunta de si el Consejo puede ordenar la cancelación del funcionamiento de las bases de datos. En cuarto lugar, la potestad de proporcionar información a las personas, acerca de sus derechos en materia de tratamiento de los datos de carácter personal y promoción del respeto de los mismos [artículo 33 bis letra h) de la "Ley de transparencia"]; en relación con esta facultad de promoción y educación, se observa que esta disposición nada señala en relación a los deberes, planteando de paso la duda respecto a la posibilidad de un cobro por servicio especializado. Y, en quinto lugar, la facultad de ejercer el control y adoptar las autorizaciones que procedan para las transferencias internacionales de datos, conforme lo establecido en la ley No $^{0} 19.628$, así como desempeñar las funciones de cooperación internacional en materia de protección de datos [artículo 33 bis letra i) "Ley de transparencia"].

\section{Tratamiento otorgado a los datospersonales en la "Ley de transparencia".}

Como in trodu c ci ón a este tema, es oportuno recordar que la "Ley de transparencia” de la Función Pública y de Acceso a la Información de la Administración del Estado (aprobada por el artículo 1 de la Ley No 20.285 del 2008), también conocida como "Ley de transparencia", es un cuerpo legal cuyo ámbito de aplicación es la información que obra en poder de los órganos del Estado (la que puede incluir datos de carácter personal) y tiene como pretensión el favorecer su conocimiento por parte de los ciudadanos, según se observa en lo anotado en su artículo 10 el cual estipula que "toda persona tiene derecho a solicitar y recibir información de cualquier órgano de la Administración del Estado, determinando además que el acceso a la información comprende el derecho de acceder a las informaciones contenidas en actos, resoluciones, actas, expedientes, contratos y acuerdos, asi como a toda 
información elaborada con presupuesto público, cualquiera sea el formato o soporte en que se obtenga, salvo las excepciones legales". En consecuencia, la transparencia administrativa permite favorecer la probidad y potenciar la participación ciudadana.

Esta "Ley de transparencia" en el artículo 21, establece como causales de secreto o reserva en cuya virtud se podrá denegar total o parcialmente el acceso a la información, cuando su publicidad afecte el cumplimiento de las funciones públicas, los derechos de las personas, la seguridad de la nación o el interés nacional. Más concretamente, el numeral $2^{\circ}$ del citado artículo 21 determina como excepción cuando "su publicidad, comunicación o conocimiento afecte los derechos de las personas, particularmente tratándose de su seguridad, su salud, la esfera de su vida privada, sus datos sensibles o derechos de carácter comercial o económico", entendiendo por tales "aquellos que el ordenamiento juridico atribuye a las personas, en título de derecho y no de simple interés".

Precisamente, dentro de la causal los derechos de las personas, caben los reconocidos por el artículo $19 \mathrm{~N}^{\circ} 4^{\circ} \mathrm{CPol}$. y por la Ley $\mathrm{N}^{\circ} 19.628$ en el ámbito del tratamiento de datos personales, que formen parte de la esfera y de la vida privada o íntima de una persona y de su familia (principalmente, el derecho de acceder a ellos, de controlarlos y de autodeterminarlos al momento de su tratamiento o procesamiento). De lo anterior se deduce que la protección legal del tratamiento de datos personales es una limitante al ejercicio del derecho de acceso a la información administrativa del artículo 10 de la "Ley de transparencia", ya que ellos, los datos nominativos, por regla general son protegidos constitucional y legalmente con una esfera de secreto o reserva ${ }^{42}$.

Acorde con lo comentado y con el propósito de ilustrar sobre el tratamiento de los datos nominativos como limitante al ejercicio del derecho de acceso a la información, en esta parte del trabajo revisaremos los siguientes aspectos: el habeas data y transparencia administrativa, los contenidos generales de la "Ley de transparencia" y su reglamento (de cara a su relación con el tratamiento de los datos personales) y los eventos en los cuales la "Ley de transparencia" permite denegar el acceso a la información.

a) En primer lugar y en este orden de ideas, debemos observar la noción del habeas data y su relación con la transparencia ad$\mathrm{m}$ in is trativa. En efecto, respecto a quien pretende acceder a los datos personales, identificamos dos posibilidades: que la solicitud de acceso sea atribuible al propio titular de estos datos o que el requerimiento de informa-

${ }^{42}$ Jijena Leiva, Renato, cit. (n. 23), p. 156. 
ción provenga de un tercero. En el primer caso, la solicitud de información estará sustentada en el habeas data procesal del artículo 12 de la Ley No 19.628, ejercido ante el responsable del registro o banco de datos personales. Precisamente, el derecho de habeas data es una garantía (incluso con rango constitucional en algunos países, pero solo reconocido legal y procesalmente en Chile) por virtud de la cual todo individuo tiene garantizado el derecho de información que le concierne personalmente, a los efectos que ella dispone, no le sea ajena y pueda actuar en consecuencia de ese conocimiento ${ }^{43}$; puntualmente, el señalado artículo 12 otorga al titular de los datos nominativos los derechos de acceso, rectificación, cancelación y bloqueo, derechos exigibles al responsable de una base o banco de datos que se dedique en forma pública o privada al tratamiento de los mismos. Para autores como Pierini y Lorences, el derecho de habeas data puede ser, en una de sus vertientes, una modalidad del derecho de acceso a la información pública ${ }^{44}$. De la lectura anterior, se desprende que cuando el titular busca acceder a sus datos, lo hace bajo un interés personal de control y autodeterminación, y no con la intención de potenciar la transparencia y la probidad en la función pública ${ }^{45}$. La segunda posibilidad (es decir, cuando el requerimiento de información provenga no del propio titular de los datos, sino de un tercero) ha sido una hipótesis de frecuente ocurrencia desde que comenzó la aplicación de la "Ley de transparencia" (como se expondrá mas adelante con el estudio de algunas decisiones emanadas por el Consejo).

b) En segundo lugar, respecto a los contenidos generales de la "Leydetransparencia" y su reglamento, de cara a su relación con el tratamiento de los datos personales, tales contenidos son enunciados en su artículo $1^{\circ}$, norma según la cual esta Ley regula el principio de transparencia de la función pública, el derecho de acceso a la información de los órganos de la Administración del Estado, los procedimientos para el ejercicio del derecho y para su amparo, y las excepciones a la publicidad de la información o las causales de reserva o secreto.

c) Desde el punto de vista de su estructura, la Ley de transparencia de la función pública y de acceso a la información de la Administración del Estado

${ }^{43}$ Quiroga Laviè, Humberto, Habeas data (Buenos Aires, Zavalia, 2001), p. 8.

${ }^{44}$ Pierini, Alicia - Lorences, Valentín, Derecho de acceso a la información (Buenos Aires, Editorial Universidad, 1999), pp. 38-41.

${ }^{45}$ Observamos entonces la diferencia entre el derecho de acceso de todos los ciudadanos para conocer los actos, contratos y documentos de los órganos de la Administración del Estado (derecho reconocido en el artículo 8 CPol. y en la "Ley de transparencia") respecto del derecho de acceso o habeas data que posee toda persona para controlar y autodeterminar el uso únicamente de sus datos y antecedentes personales y nominativos (al tenor de las disposiciones de la Ley No 19.628). 
(nombre que se otorga a esta normativa en su artículo $1 \mathrm{~N}^{\circ} 4$ ) esta divida en siete títulos que comprenden los siguientes temas: el primero contiene disposiciones generales; el segundo, alude a la publicidad de la información de los órganos de la Administración del Estado; el tercero a la transparencia activa; el título cuarto, al derecho de acceso a la información de los órganos de la Administración del Estado o transparencia pasiva; el título quinto, a la naturaleza jurídica, funciones y atribuciones del Consejo para la Transparencia; el sexto establece infracciones y sanciones; y el séptimo, contiene diversas disposiciones transitorias. En este contexto, los aspectos más relevantes contenidos en estos temas, de cara a su relación con el tratamiento de los datos personales, incluye materias tales como el principio de la transparencia en la función pública, el tipo de información que debe publicarse y transparentarse (es decir, que tiene el carácter de pública), la figura de la transparencia activa y los alcances del derecho de acceso a la información de los órganos de la Administración del Estado. A continuación y dentro del contexto enunciado, revisaremos las mencionadas materias.

En primer término entonces, tenemos que el principio de la transparencia en la función pública, en cuanto a su fundamento, autoridades y funcionarios sometidos al mismo y su definición, están consignados en los artículos 3 y 4 del texto legal. Según el artículo 3, la función pública "se ejerce con transparencia a efecto de permitir y promover el conocimiento de los procedimientos, contenidos y decisiones que se adopten en ejercicio de ella"; el artículo 4, en su primera parte, somete el cumplimiento de este principio a todas las autoridades y funcionarios de la Administración del Estado, y la misma norma, en su parte final, determina que este principio de la transparencia consiste "en respetar y cautelar la publicidad de los actos, resoluciones, procedimientos y documentos de la Administración, asi como la de sus fundamentos, y en facilitar el acceso de cualquier persona a esa información, a través de los medios y procedimientos que al efecto establezca la le".

En segundo término, el título $2^{\circ}$ (referido la publicidad de la información de los órganos de la Administración del Estado) en su artículo 5 y con base en el principio de la transparencia en la función pública, determina que información debe publicarse y transparentarse (es decir, que información es pública) disponiendo la norma perentoriamente que "los actos y resoluciones de los órganos de la Administración del Estado, sus fundamentos, los documentos que les sirvan de sustento o complemento directo y esencial, y los procedimientos que se utilicen para su dictación, son públicos, salvo las excepciones que establece esta ley en el articulo 21 y las previstas en otras leyes de quórum calificado"; de igual manera, el inciso $2^{\circ}$ del citado artículo 5 otorga carácter público a la información elaborada con presupuesto público " $y$ toda otra información" que obre en poder de los órganos de la Administración, 
cualquiera sea su formato, soporte, fecha de creación, origen, clasificación o procesamiento, a menos que esté sujeta a las excepciones señaladas. Para Jijena Leiva, la referencia a to d a o t r a in for m a c i ón debe entenderse en el sentido del inciso primero, es decir, que se trate de antecedentes que den cuenta de la gestión de los órganos de la Administración del Estado y no de datos de carácter personal ${ }^{46}$.

En tercer lugar, el ítulo $3^{\circ}$ al regular la denominada transparencia activa (es decir, a la obligación que tienen los organismos sometidos a la "Ley de transparencia" de mantener a disposición permanente del público cierta información, a través de sus sitios electrónicos) incluye entre los antecedentes que deben estar visibles en los respectivos sitios Web: "el diseño, montos asignados y criterio de acceso a los programas de subsidios y otros beneficios que entregue el respectivo órgano, además de las nóminas de beneficiarios de los programas sociales en ejecución", aclarando la norma que no se incluirán en estos antecedentes los datos sensibles, circunstancia reiterada por su Reglamento.

Desde otra perspectiva, y ya no sólo desde la óptica del deber positivo de los órganos de la Administración del Estado propio de la transparencia activa, observamos la consagración de un derecho específico para los ciudadanos o transparencia pasiva, garantía que implica la entrega de la información que no está sujeta al régimen anterior, por parte de esa Administración Pública a quien la requiera, a través de los mecanismos especialmente dispuestos para ello (en este caso, el procedimiento establecido en los artículos 12 y siguientes de la Ley en estudio).

Por último, en cuarto lugar observamos que el título $4^{\circ}$ que regula el "derecho de acceso a la información de los órganos de la Administración del Estado", en su artículo 10 otorga a "toda persona" el derecho a solicitar y recibir información de cualquiera de esos órganos, en la forma y condiciones que establece la propia "Ley de transparencia”. La norma determina además, que el acceso a la información comprende (en primer lugar) el derecho de acceder a las informaciones contenidas en actos, resoluciones, actas, expedientes, contratos y acuerdos, así como (en segundo lugar) a toda información elaborada con presupuesto público, cualquiera sea el formato o soporte en que se contenga y salvo las excepciones legales.

d) Para finalizar esta parte del trabajo (es decir, el estudio de la "Ley de

${ }^{46}$ El profesor Jijena Leiva, Renato, cit. (n. 23), p. 161, considera que si la "Ley de transparencia" ha demostrado un gran celo y cuidado de los datos personales en sus artículos 21 números $2^{\circ}$ y $5^{\circ}$ y 33 letra $\mathrm{m}$ ), de haberse querido incluir en esta enumeración genérica a los antecedentes nominativos de los ciudadanos, se habría hecho expresamente. El mismo autor recuerda que el punto de este posible alcance del inciso $2^{\circ}$ del artículo 5 , nunca fue debatido durante la tramitación parlamentaria de la Ley, y por ende debe ser analizado con extrema rigurosidad. 
transparencia") es pertinente anotar en que situaciones la nor mativa permite denegar el acceso a la información. Sobre este punto, y ante la obligación expresa para los órganos de la Administración del Estado de entregar la información a ellos requerida, la "Ley de transparencia" estipula dos eventos en los cuales podría presentarse una negativa a la solicitud de acceso: en primer término, el derecho de oposición que pueden formular los terceros dentro del marco de su artículo $20 \mathrm{y}$, en segundo término, las causales de reserva y secreto establecidas por la propia Ley.

En el primer caso (cuando estamos frente al derecho de oposición del tercero, dentro del marco del artículo 20 de la "Ley de transparencia" y el de su Reglamento), el precepto legal determina que la oposición debe presentarse por escrito y requiere expresión de causa y, además, frente a una reclamación por parte del requirente ante la negativa del suministro de la información, el tercero puede presentar descargos u observaciones al reclamo, incluyendo los fundamentos de hecho y de derecho. En efecto, entre los documentos o antecedentes con información que puede afectar los derechos de terceros, podría haber datos personales de aquellos que ampara y regula la Ley No 19.628, evento en el cual esos terceros probablemente querrán evitar la publicidad o el conocimiento de los antecedentes nominativos que a ellos aluden e identifican, ejerciendo su derecho de oposición, siempre con expresión de causa ${ }^{47}$.

En el segundo caso, ante la obligación legal impuesta a los órganos de la Administración del Estado de entregar la información a ellos requerida, la "Ley de transparencia" estipula (en asocio con el derecho de oposición del tercero consagrado en su artículo 20) una serie de causales de reserva o secreto cuya aplicación permite denegar el acceso. Estas casuales se encuentran consagradas en los números $1^{\circ}$ a $5^{\circ}$ del artículo 21 , norma que ya repasamos de manera general al revisar los fundamentos legales del deber del Estado de entregar la información. En particular, nos interesa el contenido de las

${ }^{47}$ El profesor Jijena LeIVA, Renato, cit. (n. 23), p. 34, plantea derechos de terceros contemplados en la Ley No 19.628 que constituyen "causas especificas expresables por el tercero al oponerse, tales como: (i) el que se estén solicitando antecedentes personales o nominativos, de aquellos que la ley 19.628 sujeta a la obligación general de secreto o de reserva para el servicio público en el artículo $7^{\circ}$, (ii) el que no están disponibles en fuentes de acceso público, (iii) el que una ley especial establece expresamente su calidad de antecedentes nominativos secretos (como es el caso del artículo 35 del Código Tributario), o (iv) porque son particular y especialmente reservados como los datos sensibles o personalísimos". El mismo autor sugiere una causal genérica, consiste en "ejercer el derecho esencial de controlar y autodeterminar el tratamiento y/o cesión o comunicación que se quiere hacer de sus propios antecedentes o datos personales", derecho reconocido en los artículos 4 y 12 de la ley 19.628 . 
causales de secreto o reserva estipuladas en los números 2 y 5 , de cara a su relación con el tratamiento de los datos personales.

En primer lugar, el $\mathrm{N}^{\circ} 2$ del artículo 21 de la "Ley de transparencia" establece como causal de reserva o secreto para entregar la información, cuando su publicidad, comunicación o conocimiento afecte los derechos de las personas, particularmente (mas no exclusivamente ${ }^{48}$ ) su seguridad, su salud, la esfera de su vida privada o sus derechos de carácter comercial o económico. Cuando esta causal alude a la esfera de vida privada (concepto ciertamente contrario a la noción de esfera de la vida pública) o a los derechos de carácter comercial o económico, normativamente se produce un reenvío no solo a la Ley No 19.628 (texto legal que se aboca desde su título a la protección de la vida privada, tanto en cuanto datos o antecedentes personales, sensibles o no) sino que también a otras disposiciones constitucionales, legales y reglamentarias, comenzando con el artículo $19 \mathrm{~N}^{\circ} 4^{\circ} \mathrm{CPol}$. (norma que, recordemos, asegura a todas las personas el respecto y protección a la vida privada, entre otras garantías) y siguiendo con leyes especiales que establecen su calidad de antecedentes secretos, como es el caso del artículo 35 CTrib. ${ }^{49}$.

En cuanto al origen de la reserva que nace de la necesaria protección de la vida privada, este criterio existió desde la presentación de la "Moción" parlamentaria que originó la "Ley de transparencia" En efecto, en dicha "Moción" se indicaba que "Las únicas causales en cuya virtud se podrá denegar total o parcialmente el acceso a la información son las siguientes [...] c) Cuando su comunicación o conocimiento afecte la vida privada de una persona individualizada o identificable, incluidos los expedientes médicos o sanitarios. d) Cuando puedan lesionar intereses comerciales u otros de tipo económicos, ya sean públicos o privados" 50 .

${ }^{48}$ Pese a su carácter taxativo, estas causales son de naturaleza genérica, y por ende admiten y requieren ser interpretadas. Originalmente, se consideró establecer causales específicas y detalladas, con numerosos ejemplos y referencias de situaciones que podían resultar ambiguas y extender la esfera de secreto, iniciativa que se descartó para mantener las genéricas, apoyadas en algunos ejemplos de situaciones precisas, limitadas o específicas donde se concreta la causal genérica y que aportan criterios para lograr que su aplicación sea adecuada. Ibíd., p. 179.

${ }^{49}$ Concretamente el inciso $2^{\circ}$ artículo 35 del Código Tributario, en relación con la presentación de declaraciones con el objeto de determinar la procedencia o liquidación de un impuesto, establece que: "El Director y demás funcionarios del Servicio no podrán divulgar, en forma alguna, la cuantía ofuente de las rentas, ni las pérdidas, gastos o cualesquiera dato relativos a ella, que figuren en las declaraciones obligatorias, ni permitirán que éstas o sus copias o los libros o papeles que contengan extractos o datos tomados de ellas sean conocidos por persona alguna ajena al Servicio salvo en cuanto fueren necesarios para dar cumplimiento a las disposiciones del presente Código u otras normas legales".

${ }^{50}$ Historia de la Ley $N^{o} 20.285$ sobre Acceso a la información pública (Santiago, Biblioteca del Congreso Nacional de Chile, 2008), p. 9. 
Continuando con la exposición, el carácter genérico de la causal (reiterando que la norma habla de la publicidad, comunicación o conocimiento de información que afecte particularmente, y no exclusivamente, derechos de las personas como su seguridad, su salud, etc.) podría generar la ampliación de la interpretación y aplicación de esta hipótesis de reserva y secreto, circunstancia que, en últimas, establece la posibilidad de restringir el derecho al acceso consagrado en la "Ley de transparencia". Bajo esta premisa, podrían invocarse como presuntamente afectados con la publicidad y por ende sujetos a reserva otros derechos o garantías relacionadas con la seguridad, la salud, la esfera de la vida privada o los derechos de carácter comercial o económico de una persona.

Finalmente, y en relación a las decisiones de amparo proferidas por el Consejo para la Transparencia, este organismo reconoce el carácter complementario de los artículos 33 letra $\mathrm{m}$ ) de la "Ley de transparencia" y $21 \mathrm{~N}^{\circ}$ 2 de la Ley $N^{\circ} 19.628$, subrayando que la referencia a la e $s$ fe r a $\mathrm{p}$ riv a d a debe entenderse que alude, muy especialmente, a los datos personales que tratan los órganos de la Administración Pública, considerando además que dichos datos nominativos no son parte de la esfer a social o públic a de un ciudadano, y concluyendo que será responsabilidad del Consejo establecer si el dato de carácter personal cabe dentro de esta esfera privada ${ }^{51}$.

En segundo lugar, el $N^{\circ} 5$ del artículo 21 de la "Ley de transparencia" establece como causal de reserva o secreto para entregar la información "cuando se trate de documentos, datos o informaciones que una ley de quórum calificado haya declarado reservados o secretos, de acuerdo a las causales señaladas en el artículo $8^{\circ}$ de la Constitución Política"; a su vez las causales del artículo $8^{\circ}$ se refieren al evento que la publicidad afecte el debido cumplimiento de las funciones de los órganos del Estado, los derechos de las personas, la seguridad de la Nación, o el interés nacional. Precisamente, la referencia a la afectación de los derechos de las personas, implica considerar dentro de la enunciada causal a la garantía del artículo $19 \mathrm{~N}^{\circ} 4^{\circ} \mathrm{CPol}$ y a los derechos que les reconoce la Ley No 19.628 (este último, mecanismo legal establecido para cumplir con el mandato de protección jurídica del derecho constitucional de la privacidad).

4. Solicitud de acceso a la información y tutela de los datos personales del tercero. Decisiones del Consejo para la Transparencia.

Sobre este tema, a manera de in troducción, pensamos que para comprender el trabajo desarrollado por el Consejo, en lo que atañe a la concertación entre las leyes de transparencia y la protección de los datos

${ }^{51}$ Decisión Amparo $N^{o}$ A53-09, del Consejo para la Transparencia, de 31 de julio del 2009. 
personales, es pertinente observar tres aspectos. En primer término ${ }^{52}$ (y en virtud de su facultad de emitir instrucciones generales sobre transparencia y acceso a la información por parte de los órganos de la Administración del Estado, conforme a lo establecido en el artículo 33 letra d) del estatuto sobre la transparencia) el Consejo en las Instrucciones generales sobre transparencia activa $\mathrm{N}^{\circ} 4$ y $\mathrm{N}^{\circ} 9$, efectúa las siguientes consideraciones en materia de datos personales:

i) En el numeral 1,753 (el cual regula los actos y resoluciones que tengan efectos sobre terceros) se establece que los órganos de la Administración del Estado han de abstenerse de publicar datos personales que tengan carácter reservado conforme a lo establecido en los artículos $7,10,20$ y siguientes de la Ley $N^{\circ} 19.628$, cuando deban publicar aquellos decretos, resoluciones, acuerdos de órganos administrativos publi-personales (o los actos que los lleve a efecto) u otro tipo de actos administrativos emanados de la respectiva autoridad que afecten los intereses de terceros, les impongan obligaciones o deberes de conducta o tuvieran por finalidad crear, extinguir o modificar derechos de éstos, en la medida que dichas personas sean personas naturales o jurídicas ajenos al servicio u organismo que los dicta $^{54}$.

ii) En el numeral 1,9, en lo concerniente a la publicación de las nóminas de beneficiarios de programas sociales en ejecución, debe indicarse el nombre completo de los beneficiarios, la fecha de otorgamiento del beneficio y la identificación del acto por el cual se le otorgó, excluyendo determinados datos, como por ejemplo, domicilio, teléfono y correo electrónico del beneficiario, por no ser estrictamente necesarios para individualizarlo. En un mismo sentido, en este caso no se individualizarán los beneficiarios cuando ello suponga la revelación de datos sensibles, debiendo informarse el número total de beneficiarios y las razones fundadas de la exclusión de la nómina ${ }^{55}$.

En segundo término, y continuando con el tratamiento de los datos personales y la transparencia activa, observamos los criterios expuestos en el numeral 6,3 de las Recomendaciones del Consejo para la Transparencia sobre protección de datos personales por parte de los órganos de la Administración del Estado; en esta recomendación (concerniente al tratamiento

${ }^{52}$ La armonización entre las leyes de transparencia y los estándares internacionales de protección y datos personales, ponencia del Consejo para la Transparencia, dictada el dos de junio del 2010 dentro del Seminario regional de protección de datos, Montevideo, p. 4.

${ }^{53} \mathrm{El}$ acápite 1,7 fue modificado por la Instrucción General № 7 y posteriormente, reemplazado en la Instrucción General No 9.

${ }^{54} \mathrm{La}$ armonización entre las leyes de transparencia y los estándares internacionales, cit. (n. 52), p. 4.

${ }^{55}$ Ibíd. 
de datos personales relativos a delitos, infracciones administrativas o faltas disciplinarias) se establecen las siguientes directrices:

i) Los órganos de la Administración del Estado que sometan a tratamiento datos personales relativos a condenas por delitos, infracciones administrativas o faltas disciplinarias, no pueden comunicarlos una vez prescrita la acción penal o administrativa, o cumplida o prescrita la sanción o la pena. Lo anterior, conforme a lo dispuesto en el artículo 21 de la Ley No 19.628.

ii) Como consecuencia de lo anterior, dichos órganos deben abstenerse de publicar en virtud del artículo 7 letra g) de la "Ley de transparencia", referido a los actos y resoluciones que tengan efectos sobre terceros, los datos personales relativos a condenas por delitos, infracciones administrativas o faltas disciplinarias una vez prescrita la acción penal o administrativa, o cumplida o prescrita la sanción o la pena y aplicarán, de ser procedente, el principio de divisibilidad respecto de los actos o resoluciones que los contengan.

iii) No obstante, cuando el Consejo conozca de un reclamo por incumplimiento de los deberes de transparencia activa o de un amparo por denegación de acceso a la información, podrá autorizar la comunicación de este tipo de datos cuando así lo exija el interés público, en aplicación de la "Ley de transparencia".

iv) Finalmente, se exceptúa de la prohibición de comunicación, los casos en que esa información sea solicitada a los órganos de la Administración del Estado por los Tribunales de Justicia u otros organismos públicos dentro del ámbito de su competencia, organismos que deben guardar respecto de ella la debida reserva o secreto, siendo aplicables los artículos 5, 7, 11 y 18 de la Ley No 19.628.

En tercer lugar, frente a una solicitud de información que contenga datos de carácter personal (y al pretender establecer que criterios aplica el Consejo para la Transparencia, a efecto de decidir si prevalece la protección de la vida privada o el interés público cuando se debe dar a conocer la información requerida ${ }^{56}$ ), pensamos que el organismo encargado de la transparencia ha buscado desarrollar un trabajo de armonización. En este intento de conciliación, se pretende que la transparencia y la publicidad ocasionen la mínima y

\footnotetext{
${ }^{56}$ Como ya se mencionó, al explicar el tratamiento normativo de la solicitud de acceso a la información y los derechos de terceros dentro del marco de la "Ley de transparencia” y su Reglamento, ante la existencia de derechos de terceros que puedan verse afectados, los señalados textos legales establecen la obligación del órgano requerido de notificar a ese tercero, el cual puede oponerse a la entrega de la información en forma escrita y con expresión de causa; ahora bien, si el solicitante no estuviere de acuerdo, deducirá el reclamo correspondiente, siendo en definitiva el Consejo el encargado de decidir si prevalece el interés público en conocer la información o el interés personal que implicaría denegarla.
} 
necesaria divulgación de los datos personales. Continuando entonces con el desarrollo del presente documento, enunciaremos algunas de las decisiones que el Consejo para la Transparencia ha emitido, dentro de esta labor de conciliación entre el derecho de acceso a la información y la protección de los datos personales.

Precisamente y dentro de la labor de armonización, en diversos casos el derecho de acceso a la información recayó en datos de terceros, lo que provocó un choque jurídico entre estas nociones, situación que tiende a ser mas compleja considerando que la legislación chilena no exige acreditar un interés directo particular o específico, o una afectación personal a aquel que solicita la información.

En conclusión, para el Consejo la solución en el caso chileno dependerá de que la entrega de la información aporte a la publicidad y transparencia de la función pública, o sea, que efectivamente el control ciudadano se ejerza respecto de la administración y no contra ciudadanos determinados ${ }^{57}$. En este contexto, a continuación anotamos las tendencias observadas en la jurisprudencia del Consejo, comentando temas puntuales como el tratamiento de algunas clases de datos de carácter personal (como por ejemplo la ficha clínica y la identidad de las personas fallecidas, la información de los menores de edad, la información de las personas jurídicas, el domicilio como dato personal y dato sensible, y el nombre como dato de identificación); el tratamiento de algunos datos personales sensibles (concretamente la salud y la afiliación política); el acceso del titular de los datos personales a través de la "Ley de transparencia" los datos nominativos y la transparencia activa; algunas hipótesis sobre datos personales, información entregada vía "Ley de transparencia" y terceros; el tratamiento del rol único tributario; la situación del correo electrónico; y las decisiones del Consejo para la Transparencia y solicitudes referidas a información sobre concursos para proveer cargos de funcionarios públicos.

\section{Tendencias observadas en la jurisprudencia del Consejo para la Trans- parencia.}

a) Comencemos el estudio de las tendencias observadas en la jurisprudencia del Consejo, comentando el tratamiento puntual de algunas clases de datos de carácter personal, concretamente la ficha clínica y la identidad de las personas fallecidas, la información de los menores de edad, la información de las personas jurídicas, el domicilio como dato personal y dato sensible, y el nombre como dato de identificación.

i) Respectoalaficha clínica de las personas fallecidas, el

${ }^{57}$ La armonización entre las leyes de transparencia y los estándares internacionales, cit. (n. 52), pp. $4 \mathrm{~s}$. 
Consejo para la Transparencia estima que los parientes del causante pueden acceder a su ficha clínica en determinadas circunstancias. En efecto, para este órgano el que la persona fallecida deje de ser titular de un derecho $0^{58}$, no implica que puedan tratarse sus datos sensibles, ya que ello podría significar un perjuicio a su honor cuyo resarcimiento puede alegarse por sus herederos. De esta forma, la honra de las personas fallecidas se proyecta como un derecho propio de sus familiares, quienes tendrán el derecho a conocer tal información.

Igualmente, el Consejo ha manifestado que las personas que pueden acceder a la ficha clínica deben cumplir con las siguientes condiciones: “a) Ser heredera del fallecido, de acuerdo a lo dispuesto en el artículo 983 del Código Civil, o que actúa en representación de uno o más herederos./ b) Tener una legitimación activa para ejercer otros derechos que supongan el acceso previo a la ficha clínica del difunto"s9.

ii) En relación a laidentidad del fallecido, el Consejo considera que esta identidad no constituye un dato sensible, toda vez que con la muerte de la persona, se extingue su derecho fundamental a la protección de datos de carácter personal. Además, estima el Consejo que tampoco estaríamos frente a un dato personal que se haya recolectado en vida de los fallecidos, sino que el dato mismo es la muerte de la persona por lo que, en ningún caso, se trataría de un dato personal y, por ende, tampoco sensible ${ }^{60}$.

iii) Respecto a los datos de los menores de edad, el organismo encargado de la transparencia ha sido especialmente riguroso en el tratamiento de este tipo de información personal. En efecto, para el Consejo los datos referidos exclusivamente a menores de edad, merecen una especial protección en virtud del principio de interés superior del niño. En este contexto, el mismo organismo ha recurrido a la aplicación del "test" de daño (con el objeto de determinar si la divulgación de la información solicitada, expondría al conocimiento público situaciones relativas a la esfera de privacidad de menores de edad, lo que representaría un daño presente, probable y específico) y del test de interés público (a fin de estimar si la revelación de

${ }^{58}$ El Consejo ha establecido que una persona fallecida no es titular de datos personales a la luz de lo dispuesto en el artículo 2 letra ñ) de la Ley No 19.628, al no tratarse de una persona natural. Ibíd.

${ }^{59}$ Concretamente, esta materia es tratada en la Decisión Amparo № C322-10, del 27 de agosto de 2010 y en la Decisión Amparo No C556-10, del 26 de noviembre de 2010. Como referencia, entre las decisiones más recientes en las que se examina el tema, tenemos la Decisión Amparo No C1586-12, del 30 de enero de 2013 y la Decisión Amparo No C700-12, del 23 de noviembre de 2012.

${ }^{60}$ Decisión Amparo No C64-10, del 11 de junio de 2010 
la información, implicaría o no un perjuicio sustancial a la posibilidad de ejercer un adecuado control social) ${ }^{61}$.

En esta labor protectora, el Consejo incluso ha tenido en cuenta tratados internacionales, como es el caso de la Convención de Derechos del Niño que en su artículo 16,1 establece que: "Ningún niño será objeto de injerencias arbitrarias o ilegales en su vida privada, su familia, su domicilio o su correspondencia, ni de ataques ilegales a su honra y reputación" 62 .

Debemos agregar, que se ha admitido la entrega de datos personales del menor de edad a sus padres, siempre que exista autorización legar en los términos exigidos por los artículos 4 y 7 de la Ley No $19.628^{63}$.

iv) En lo que concierne a las pe r s o n a s ju ríd ic a s, el Consejo reitera que la Ley No 19.628 no es aplicable a estas. Sin embargo, ha reconocido ${ }^{64}$ la existencia de un derecho al honor por parte de las personas jurídicas privadas, derecho que las ha hecho acreedoras de algún nivel de protección ${ }^{65}$.

$v$ ) Respecto al tratamientodeld omicilio como dato personal y dat o s e n sible, el Consejo en sus decisiones subraya que el domicilio de los terceros es un dato personal, al cual solo puede accederse con la autorización de su titular o cuando la ley lo permita (por ejemplo, cuando esta información se encuentra inserta en la red familiar en poder de la Subsecretaria de Bienes Nacionales ${ }^{66}$. El organismo incluso le ha otorgado al domicilio de los terceros el carácter de dato sensible, en aplicación del artículo 2 letra g) de la Ley $\mathrm{N}^{\circ}$ 19.628, como ocurre por ejemplo cuando dicha información hace parte de la base de datos de la Encuesta de calidad de vida y salud elaborada por el Ministerio de Salud, caso en el cual este domicilio (concretamente la dirección de la vivienda seleccionada) recibe el mismo tratamiento de información sensible que posee el registro de personas en el hogar, parentesco, nivel de educación y estado conyugal, así como preguntas sobre la vida sexual del encuestado, estado de salud, entre otros ${ }^{67}$.

vi) Finalmente, yen relación al n o mbre como dato de identific a c i ó $n$, el tratamiento otorgado por el Consejo a este tipo de información

${ }^{61}$ Decisión Amparo No C816-10, del 7 de enero de 2011.

${ }^{62}$ Decisión Amparo No C392-12, del 11 de julio del 2012.

${ }^{63}$ Concretamente, esta materia es tratada en la Decisión Amparo No C967-12, del 12 de octubre de 2012. Como referencia, entre las decisiones más recientes en las que se examina el tema (datos de los menores de edad) tenemos la Decisión Amparo No C475-12, del 10 de agosto de 2012 y la Decisión Amparo No C265-12 del 29, de junio de 2012.

${ }^{64}$ Protección de datos personales, cit. (n. 1), p. 12.

${ }^{65}$ Como referencia, entre las decisiones de amparo más recientes en las que se examina el tema, tenemos la $\mathrm{N}^{\circ} \mathrm{C} 1482-12$ del 18 de enero de 2013

${ }^{66}$ Decisión Amparo No A33-09, del 30 de junio de 2009.

${ }^{67}$ Decisión Amparo No A190-09, del 29 de septiembre de 2009. 
(por ejemplo, cuando se pretende determinar la identidad de quien formula un reclamo o denuncia ante organismos de fiscalización de la Administración del Estado) varía según la naturaleza de su titular. En primer lugar, el Consejo ha establecido que en el caso de los reclamos o denuncias presentados por autoridades públicas, o por funcionarios públicos en el ejercicio de su cargo o función pública, no puede sostenerse que la revelación de sus identidades pueda causarles algún perjuicio, de tal forma que la identidad de estos debe ser revelada sin más, entregando los nombres completos. En segundo lugar, respecto a los particulares notificados que se oponen en tiempo y forma a la entrega de la información, el Consejo ha estimado la denegación del acceso a la información en los términos del artículo 20 de la "Ley de transparencia" (ordenándose, en caso contrario, la entrega de la identidad al reclamante) ${ }^{68}$. En tercer lugar, y tal como se comenta en la Decisión de Amparo No C122512 , frente a denuncias presentadas bajo un nombre falso, el organismo encargado de la transparencia ha señalado que no se percibe un interés público en conocer dicha información. Igualmente subraya que no resulta de interés público el nombre de la persona que ha formulado la denuncia, por cuanto los particulares que ponen en conocimiento de las autoridades determinados hechos que puedan constituir infracciones o presuntos ilícitos, merecen que su identidad sea protegida, más allá de que la denuncia sea o no plausible (señalando, por ejemplo, que revelar la identidad de quienes formulan denuncias a la autoridad inhibiría a los que pudieren realizar denuncias en el futuro $)^{69}$. Sin embargo, esta opinión del Consejo ha sido desestimada por los Tribunales. En efecto, la mencionada Decisión de Amparo No C1225-12 fue objeto de un reclamo de ilegalidad interpuesto ante la Corte de Apelaciones de Punta Arenas (rol 262-2012); en resumen, el Tribunal acogió el reclamo, señalando que no divisaba en qué forma la entrega de un nombre falso de un denunciante, podría inhibir futuras denuncias o reclamos, situación que ocasionaría un desmedro en las facultades fiscalizadoras de los Órganos de la Administración del Estado, toda vez que en el caso de autos dicha fiscalización efectivamente se realizó con resultados negativos, y muy por el contrario existiría un real perjuicio con la no entrega de dicha individualización, toda vez que el recurrente se había visto impedido de concurrir al Ministerio Público con el objeto de denunciar un posible delito de usurpación de nombre. La Corte concluye, estimando que en la especie tampoco se presenta la causal de excepción contenida en el artículo $21 \mathrm{~N}^{\circ} 1$ de la "Ley de transparencia"

b) Otro tema analizado en la jurisprudencia del Consejo, es el tratamiento

${ }^{68}$ Decisión Amparo No A91-09, del 14 de agosto de 2009.

${ }^{69}$ Decisión Amparo № C1225-12, del 28 de noviembre de 2012. 
de algunosdatos personales sensibles, concretamente la salud y la afiliación política

En lo referente a la salud, el Consejo ha considerado que tanto las licencias médicas (incluyendo la fecha de emisión de las mismas y la de recepción por parte del empleador, su número identificatorio, así como el número de días prescrito y la institución a la cual se deben despachar ${ }^{70}$ como la ficha clínica de un paciente ${ }^{71}$ y el listado de personas a las cuales se les haya diagnosticado una enfermedad determinada, constituyen datos sensibles ${ }^{72}$, por referirse a estados de salud físicos o psíquicos, dando cuenta así de datos personales que se refieren a hechos o circunstancias de su vida privada o íntima; de tal manera que, frente a los requerimientos de este tipo de información, se ha ordenado la reserva de la misma ${ }^{73}$. En relación a la afiliación política, el Consejo ha aplicado el artículo $21 \mathrm{~N}^{\circ} 5$ de la "Ley de transparencia" en relación con lo prescrito por el artículo 2 letra g) de la Ley No 19.628, que califica esta información como un dato sensible (por ejemplo, ante el requerimiento de la afiliación política de los integrantes de un Comité Evaluador de Fondos Concursables $)^{74}$.

c) En relación al acceso del titular de los datos personales a través de la "Ley de transparencia", la jurisprudencia subraya que el artículo 12 de la Ley No 19.658 consagra como uno de los derechos del titular de los datos de carácter personal, el de exigir a quien sea responsable de un banco (dedicado en forma pública o privada al tratamiento de datos personales) información sobre los datos relativos a su persona, su procedencia y destinatario, el propósito del almacenamiento y la individualización de las personas u organismos a los cuales sus datos son transmitidos regularmente. Esta garantía es también conocida como derecho de acceso del titular de datos nominativos y se comprende dentro del habeas data ${ }^{75}$. Lo anterior, ha sido recogido en el punto 5.1 de las Recomendaciones del Consejo para la Transparencia sobre protección de datos personales por parte de los órganos de la Administración del Estado ${ }^{76}$.

${ }^{70}$ Decisión Amparo No C267-10, del 3 de agosto de 2010.

${ }^{71}$ Decisión Amparo No C240-10, del 24 de agosto de 2010.

${ }^{72}$ Decisión Amparo No A211-09, del 11 de septiembre de 2009.

${ }^{73}$ Como referencia, entre las decisiones de amparo más recientes en las que se estudia el tema (salud como dato sensible), tenemos la $\mathrm{N}^{\circ} \mathrm{C} 1796-12$, del 8 de marzo de 2013 y la No C1282-12 del 14 de diciembre de 2012.

${ }^{74}$ Decisión Amparo No A152-09, del 22 de septiembre de 2009.

${ }^{75}$ Decisión Amparo No C323-10, del 30 de julio de 2010.

${ }^{76} \mathrm{Al}$ respecto, es pertinente recordar la parte final de este punto 5,1 , el cual determina que cuando en el ejercicio del derecho de acceso a la información pública establecido en la "Ley de transparencia", se soliciten antecedentes que, obrando en poder de la Administración, contengan datos personales de los que es titular el solicitante, se 
Igualmente, el Consejo ${ }^{77}$ admite la entrega de datos de carácter sensible (por ejemplo copia de las actas e informes relacionados con la persona del reclamante, evacuados en las sesiones del consejo técnico de un centro penitenciario), siempre que el solicitante sea el titular de la información requerida ${ }^{78}$.

d) Respecto a los datos personales y la transparencia a c t iv a, el Consejo en su jurisprudencia ha manifestado que, siendo competente para pronunciarse sobre el cumplimiento de la Ley No 19.628 (al establecer el artículo 8 de la "Ley de transparencia" que la acción de reclamación resulta procedente cuando el organismo público no informa en sus sitios electrónicos los antecedente prescritos en el artículo 7 de esta última normativa) debe entenderse que el incumplimiento de la obligación de informar del organismo no se reduce a verificar la concurrencia de la acción positiva de publicar información en la página $\mathrm{Web}$ del Servicio, sino que también incluye el incumplimiento de la obligación de divulgar información en los términos y dentro de los límites previstos por el ordenamiento jurídico, lo que supone respetar las causales de reserva contempladas en el artículo 21 de la "Ley de transparencia" y las disposiciones aplicables de la Ley No 19.628. Conforme a lo anterior, en aplicación del artículo 47 de la normativa sobre transparencia, el Consejo puede sancionar a la autoridad ${ }^{79}$ que "injustificadamente: (i) no divulgue la información requerida por el articulo $7^{\circ}$; (ii) lo haga comunicando datos personales cuya comunicación no responde a la finalidad autorizada por el legislador; o (iii) divulgue información secreta o reservada"80.

e) En relación a los datos personales, la información entregada vía "Ley de transparencia" y los terceros ${ }^{81}$, enesta parte del repaso a la jurisprudencia del Consejo comentaremos la conducción dada a tres situaciones: el tratamiento otorgado al requerimiento de copias de las solicitudes de acceso a la información (presentadas durante un cierto

aplicará el procedimiento establecido en dicha Ley, incluyendo la posibilidad de recurrir de amparo ante el Consejo. No obstante ello, en lo relativo a la gratuidad del acceso, se observará lo dispuesto en la Ley No 19.628 .

${ }_{77}^{77}$ Decisión Amparo No C426-10, 13 de noviembre del 2010.

${ }^{78}$ En lo concerniente al tema en estudio (acceso del titular de datos personales a través de la "Ley de transparencia") otras decisiones de amparo concordantes con las ya comentadas son las $\mathrm{N}^{\circ} \mathrm{C} 915-10$, del 4 de marzo de 2011, y las $\mathrm{N}^{\circ} \mathrm{C} 49-11$ y No $\mathrm{C} 103$ 11, del 11 de marzo de 2011.

${ }^{79}$ Decisión Amparo No C579-10, del 16 de noviembre de 2010.

${ }^{80}$ Como referencia, entre las decisiones de amparo más recientes en las que se examina el tema, tenemos la $\mathrm{N}^{\circ} \mathrm{C} 1738-12$, del 28 de febrero del 2013; y las $\mathrm{N}^{\circ} \mathrm{C} 550-12$, C551, C552 y C555, del 25 de julio del 2012.

${ }^{81}$ Protección de datos personales, cit. (n. 1), pp. 17-19. 
período de tiempo y ante determinados órganos de la Administración del Estado), el tratamiento dado a la solicitud de las resoluciones que decidían tales requerimientos, y el manejo otorgado a la petición de los documentos entregados como respuesta a las solicitudes.

En primer lugar, el Consejo ha reconocido que no obstante que las solicitudes de acceso fueran complemento directo de un acto administrativo, en virtud de lo dispuesto por los artículos 4, 9, 10 y 20 de la Ley No 19.628 la comunicación a terceros de algunos de los datos contenidos en ellas, se encontraba vedada a los órganos de la Administración.

En segundo lugar, a la misma conclusión se llegó en relación con las resoluciones pronunciadas con motivo de las solicitudes de acceso, toda vez que éstas podrían reproducir, a juicio del Consejo, los datos personales que el solicitante incorporó a su presentación para su mejor individualización. Además, el citado organismo ha estimado que la asociación de la identidad del solicitante con lo pedido dentro del texto de la resolución, puede incluso revelar datos sensibles de las personas o afectar sus derechos personales.

En tercer término, y tratándose de los requerimientos acerca de documentos que los órganos administrativos ya han entregado a terceros, el órgano rector de la transparencia ha indicado que de ciertas decisiones en determinadas materias (concretamente decisiones de amparo referidas a las fichas clínicas, los postulantes a cargos en la Administración, la petición de datos personales reservados por parte de su titular y el acceso al sumario administrativo por el inculpado) podía extraerse como criterio jurisprudencial, el que existiría cierta información que obra en poder de órganos de la Administración a la que sólo deben acceder sujetos determinados ${ }^{82}$. Esto ocurriría (agrega el Consejo) o porque el ordenamiento jurídico protege el derecho de la persona a excluir a terceros de su conocimiento o porque se estima que el acceso universal puede afectar el debido funcionamiento del órgano. En las decisiones analizadas se ha declarado implícitamente la reserva de los documentos requeridos con carácter general, identificando al solicitante como un sujeto excepcionalmente autorizado para acceder a ellos (en esta hipótesis la resolución del órgano administrativo que ordenaba la entrega de la información, no estaba declarando el carácter público de los documentos requeridos, sino sólo el acceso a favor de un determinado sujeto).

${ }^{82}$ Sobre este punto, los fallos que concretamente tiene en cuenta el Consejo para la Transparencia son los siguientes: i) Decisiones de Amparo No C322-10, No C556-10 y No C596-10, sobre fichas clínicas; ii) Decisiones de Amparo No C53-10, No C91-10 y No C190-10, sobre postulantes a cargos en la Administración (antecedentes de un concurso público); iii) Decisiones de Amparo No C323-10 y No C426-10, sobre petición de datos personales reservados por parte de su titular; y iv) Decisión Amparo No C858-10, sobre acceso al sumario administrativo por el inculpado. 
En base a lo expuesto, el Consejo identificó las siguientes tareas de los órganos de la Administración para dar respuesta a las solicitudes del reclamante: reproducir y revisar las solicitudes y resoluciones correspondientes a las fechas indicadas; tachar en ellas los datos que permiten la individualización del solicitante; identificar los documentos que contienen información reservada ${ }^{83}$; comunicar los datos requeridos acerca de la tramitación de las solicitudes de información presentadas a cada organismo; atendida la forma de entrega requerida por el solicitante, reproducir digitalmente cada una de las solicitudes y resoluciones tachadas, así como los documentos solicitados (en este sentido, teniendo en cuenta el nivel de sistematización en que se encontraba la información solicitada, para determinar la concurrencia de la causal de reserva invocada debía atenderse, exclusivamente, al volumen de información involucrado, circunstancia que implica contextualizar la supuesta distracción indebida de funciones manifestada en la carga de trabajo de los funcionarios encargados, el tiempo estimado en recopilar, evaluar, reproducir y tachar la información requerida, etc. $)^{84}$.

f) En relación al tratamiento del rol único tributario, ante requerimientos de información la jurisprudencia del Consejo para la Transparencia plantea dos hipótesis: por un lado, el tratamiento del rol ú n i co tribut a ri o de funcionarios públicos, y por otro, el tratamiento del rol ú n ico tributario de los terceros ajenos a la administración.

En la primera hipótesis, el Consejo ha señalado que si bien la condición de funcionario del Estado supone un estándar de escrutinio público (en el que la privacidad debe ceder en pos del necesario control social) ello no obsta a que respecto de los datos sensibles y aquellos datos personales (tales como el rol ú n ico tributario) estos deban ser resguardados en aplicación de las normas contenidas en la Ley No 19.628. De esta forma, en razón de lo manifestado por el mencionado organismo en su jurisprudencia y en virtud del principio de divisibilidad contemplado en el artículo 11 letra e) de la "Ley de transparencia", el acceso a la información exige tarjar previamente

\footnotetext{
${ }^{83}$ Este proceso de divisibilidad responde, según el criterio de la jurisprudencia, a la omisión del procedimiento de oposición contenido en el artículo 20 de la "Ley de transparencia”, toda vez que al revisar las solicitudes en comento, los órganos requeridos debieron verificar si la divulgación de la información podría afectar los derechos de los terceros (solicitantes) y, en tal caso, notificar a éstos el requerimiento de información. Ahora bien, dicho reproche no cabe en los casos en que se estime que abordar dicho procedimiento de notificación afectaría el debido cumplimiento de sus funciones, en los términos del artículo $21 \mathrm{~N}^{\circ} 1$ de la "Ley de transparencia", caso en que podía haberse denegado el acceso a la información en virtud de dicha causal.

${ }^{84}$ Como referencia, entre las decisiones de amparo más recientes en las que se examina el tema (datos personales, información entregada vía "Ley de transparencia" y terceros) tenemos la No C1788-12 y la No C1791-12, del 6 marzo del 2013.
} 
la cédula de identidad de los funcionarios ${ }^{85}$. El Consejo además estima que, por tratarse de un dato de carácter personal, su difusión implica una posible afectación a los derechos de terceros, de modo que para proceder a su entrega sería necesario aplicar previamente el procedimiento de notificación del derecho de oposición del artículo 20 de la "Ley de transparencia" ${ }^{86}$.

En la segunda hipótesis, cuando dentro de la información que se ordena entregar está contenido el rol ú n ico tributario de personas naturales que no son funcionarios públicos, el Consejo ha ordenado el resguardo de dicho antecedente pues se le considera dato personal, al cual sólo puede accederse con la autorización de su titular o cuando la ley lo permite, de acuerdo al artículo $4^{\circ}$ de la Ley $N^{\circ} 19.658^{87}$. Este criterio incluso es aplicado a beneficiarios del Estado, (por ejemplo de becas) pues aún cuando este hecho hace que se reduzca el ámbito de la privacidad de estas personas en aras del necesario control social que debe propiciarse en la materia, no se observa de qué modo el conocer el rol ú n i co tributa ri o de los beneficiarios pueda revestir interés público para el ejercicio de dicho control ${ }^{88}$.

Finalmente, el organismo ha expresado que no se requiere el consentimiento expreso de sus titulares para proceder a la entrega, cuando el rol único tributario es un dato recolectado de fuentes accesibles al público $^{89}$.

g) Otro tema observado en las decisiones del Consejo, es el tratamiento del correo electrónico como dato de carácter nomi$\mathrm{n}$ a tivo. Sobre este particular, la jurisprudencia abarca dos aspectos: el tratamiento de la dirección electrónica y del contenido del correo electrónico.

En el primer caso, el Consejo ha estimado que la dirección de correo electrónico constituye un dato personal de conformidad con lo previsto en la Ley No 19.628, por lo que debe protegerse su divulgación ${ }^{11}$.

En el segundo caso (es decir, en cuanto al contenido del $e$ mail), para el órgano encargado de la transparencia los correos electrónicos de funcionarios del Estado, enviados o recibidos desde su casilla institucional y en ejercicio

${ }^{85}$ Decisión Amparo No C957-12, 10 de octubre de 2012.

${ }^{86}$ Decisión Amparo No A10-09 y Decisión Amparo No A126-09, 31 de julio del 2009.

${ }^{87}$ Protección de datos personales, cit. (n. 1), pp. 19 s.

${ }^{88}$ Ibíd.

${ }^{89}$ Decisión Amparo No C521-10, del 1 de octubre de 2010.

${ }^{90}$ Como referencia, entre las decisiones de amparo más recientes en las que se estudia el tema (tratamiento del rol único tributario) tenemos la $\mathrm{N}^{\circ} \mathrm{C} 1773-12$, del 8 de febrero de 2013; las $\mathrm{N}^{\circ} \mathrm{C} 1463-12$, $\mathrm{N}^{\circ} \mathrm{C} 1468-12$ y No $\mathrm{C} 1469-12$, del 18 de enero de 2013; y la No C1164-12, del 23 de noviembre de 2012.

${ }^{91}$ Protección de datos personales, cit. (n. 1), p. 20. 
de funciones públicas (esto es, excluyendo aquellos que tengan que ver con su vida privada o personal) son públicos si no se acredita la concurrencia de una causal legal específica de secreto o reserva. Así, para el Consejo el secreto o la reserva de la información depende del contenido y no del continente (observando que sólo de esta forma es posible el control y la participación ciudadana en el ejercicio de las funciones públicas y el adecuado ejercicio de la libertad de expresión). El organismo estima además que frente a correos electrónicos en los que se expongan o puedan exponer antecedentes acerca de la intimidad o la vida privada de su emisor, su receptor o un tercero, o que no se relacionen con el ejercicio de funciones públicas, debe aplicarse el principio de la divisibilidad ${ }^{2293}$. El Consejo agrega que, así como no puede sostenerse que todos los correos electrónicos de las autoridades son reservados no cabe, tampoco, estimar que todos esos correos son públicos ${ }^{94}$.

Finalmente, para el órgano rector de la transparencia, y en relación a cartas enviadas por un particular a la casilla de correos electrónicos de un funcionario público ${ }^{95}$, éstas comunicaciones no pueden estimarse privadas (en los términos del artículo $19 \mathrm{~N}^{\circ} 5 \mathrm{CPol}$.) siempre que sus contenidos

${ }^{92}$ Concretamente, esta opinión del Consejo es expresada en la Decisión de Amparo $\mathrm{N}^{\circ} \mathrm{C} 1101-11$, del 16 de marzo de 2012, de trascendencia mediática ya que involucró directamente a un ministro de Estado. Consejo para la Transparencia, Entrega decisión en caso sobre correos electrónicos de ministro Larroulet, 4 de abril del 2012 [visible en Internet: http://www.consejotransparencia.cl/consejo-para-la-transparenciaentrega-decision-en-caso-sobre-correos-electronicos-de-ministro-larroulet/consejo/2012-04-04/162926.html, consultado el 12 de junio del 2012].

${ }^{93}$ Sobre el particular, es de anotar que el Tribunal Constitucional, en la sentencia rol No 2246-2012 del 31 de enero de 2013, declaró inaplicable el inciso $2^{\circ}$ del artículo 5 de la "Ley de transparencia". Este caso referido a la norma señalada se decide atendiendo a los artículos 8 y $19 \mathrm{~N}^{\circ} 5 \mathrm{CPol}$. En efecto, con fecha 31 de enero de 2013, la máxima instancia constitucional acogió el requerimiento deducido por el subsecretario general de la Presidencia, Claudio Alvarado Andrade, declarando inaplicable para el caso concreto el inciso $2^{\circ}$ del artículo 5 de la "Ley de Transparencia" en la substanciación del reclamo de ilegalidad interpuesto ante la Corte de Apelaciones de Santiago, en causa rol $N^{\circ}$ 2496-2012. Dicho reclamo de ilegalidad fue deducido en contra de la Decisión de Amparo No C1101-11.

${ }^{94}$ Decisiones de Amparo como la No C591-12, del 8 de agosto de 2012, vinieron a ratificar esta opinión del Consejo para la Transparencia, al señalarse que no todos los correos electrónicos de funcionarios públicos enviados o remitidos desde sus casillas institucionales son, en principio, públicos, sino que sólo lo serían aquellos que dicen relación con el ejercicio de la función pública.

${ }^{95}$ Como referencia, entre las decisiones de amparo más recientes en las que se examina el tema (correo electrónico) tenemos la № C1606-12, del 13 de marzo de 2013; la No C1482-11, del 29 de junio de 2012 y la No C939-12, del 7 de diciembre de 2012. 
tengan como objeto exclusivo la relación jurídica que mantiene el particular con la Administración ${ }^{96}$.

b) Para finalizar, una materia ampliamente tratada en las decisiones del Consejo para la Transparencia, son las solicitudes referidas a información sobre concursos para proveer cargos de funcionarios públicos.

Sobre este asunto, el Consejo ha entendido que, sin perjuicio de que se trate de antecedentes previos a la adopción de una resolución, medida o política, la cual sería el nombramiento del funcionario respectivo, en aplicación de la "Ley de transparencia", dicha reserva termina una vez finalizado el concurso. Siendo así, una vez concluido el proceso de selección los antecedentes pasarían a ser públicos, por lo que se debe acceder a la entrega de aquella información perteneciente al solicitante y de los datos pertenecientes a quien finalmente fue seleccionado para desempeñar el cargo concursado ${ }^{97}$. Respecto a la información de los demás postulantes que no fueron seleccionados, el Consejo ha considerado que podría existir afectación de los derechos de quienes participaron en el concurso ${ }^{98}$, por lo que sería aplicable el procedimiento de notificación de su derecho de oposición ${ }^{99}$, agregando que la postulación a un cargo público no tiene por qué significar exposición a la comunidad en caso de no resultar exitosa ${ }^{100}$, siendo posible la entrega de datos en aquellos casos en que el tercero acceda a ello expresamente y cuando no hubiese oposición dentro del plazo correspondiente en los términos del inciso final del artículo 20 de la "Ley de transparencia".

En definitiva ${ }^{101}$, la postura del Consejo para la Transparencia indica que la información respecto de los concursos públicos, por tratarse de información indispensable para el control de los procesos de selección, es de carácter público. Es por ello que el órgano requerido debe acceder a la entrega de antecedentes, tales como la historia curricular del candidato, la descripción de la motivación, el puntaje asignado a cada atributo del perfil por la Consultora

${ }^{96}$ Protección de datos personales, cit. (n. 1), p. 20.

${ }^{97}$ Decisión Amparo No A35-09, del 11 de agosto de 2009 y Decisión Amparo No C488-09, del 27 de abril de 2010.

${ }_{98}^{98}$ Decisión Amparo No A35-09, del 11 de agosto de 2009 y Decisión Amparo No C592-09, del 27 de julio de 2010.

${ }_{99}^{9}$ Decisión Amparo № C368-10, del 3 de diciembre de 2010 y Decisión Amparo No C827-10, del 25 de enero de 2011.

${ }^{100}$ Decisión Amparo No A90-09, del 23 de febrero del 2010 y Decisión Amparo No C130-10, del 13 de septiembre de 2010.

${ }^{101}$ Boletín Jurídico de la Comisión de Probidad y Transparencia, Secretaría General de la Presidencia, 3 [visible en http://www.probidadytransparencia.gob.cl/assets/files/ documentos/boletines/juridico/Boletin_Juridico_3.html, consultado el 20 de abril del 2012]. 
y, en su caso, el puntaje asignado por el Comité de Selección o Consejo de Alta Dirección Pública.

En este orden de ideas, ¿qué aspectos solicitados deben ser resguardados a pesar del carácter público de la información? La jurisprudencia del Consejo manifiesta que deben tarjarse aquellos datos de carácter personal, como el rol único tributario, domicilio, estado civil, teléfonos y correos electrónicos ${ }^{102}$. De igual forma, deben resguardarse los antecedentes relativos a la evaluación psicológica, la evaluación descriptiva de atributos y la conclusión del informe psicolaboral (síntesis de fortalezas, oportunidades, debilidades y amenazas); y finalmente las referencias que dentro del proceso efectúen terceros ${ }^{103}$.

Para concluir este punto, la Corte de Apelaciones de Santiago (al resolver dos reclamos de ilegalidad contra las Decisiones de Amparo No A29-09 y No A35-09) reconoció que, aun cuando la "Ley de transparencia" indica que la confidencialidad del proceso termina al finalizar el concurso, los artículos 50 y 55 de la Ley No 19.882 que crean el Sistema de Alta Dirección Pública constituyen norma expresa que restringe dicha publicidad. De esta manera, aun cuando la decisión adoptada por la autoridad será pública, no lo será el procedimiento para dictarla. Así, en el fallo examinado la Corte declaró que el Consejo habría excedido su competencia, considerando que debería haber cumplido su obligación de resguardar la privacidad de la información de terceros que participan en los procesos de selección, denegando el acceso a la información solicitada ${ }^{104}$.

\section{CONCLUSIONES}

$1^{\circ}$ Confirmada la tensión entre el acceso a la información pública y la protección de los datos de carácter personal (tensión evidenciada a partir de la entrada en vigencia de la "Ley de transparencia"), a efecto de superar cualquier conflicto entre estas nociones, debemos determinar el carácter equivalente o no de tales derechos, interrogante cuya respuesta solo será posible ejecutando un estudio sistemático de la materia.

$2^{\circ}$ En este contexto, posibilidad de establecer concretamente hasta dónde

${ }^{102}$ Decisión Amparo $N^{\circ}$ C368-10, del 3 de diciembre de 2010.

${ }^{103}$ Boletín Jurídico, cit. (n. 101).

${ }^{104}$ Sentencia de la Cuarta Sala de la Corte de Apelaciones de Santiago, rol No 9432010, del 3 de septiembre del 2010. Como complemento de lo comentado, y a título de referencia, entre las decisiones de amparo más recientes en las que se examina el tema (información sobre concursos para proveer cargos de funcionarios públicos) tenemos la $N^{\circ}$ C1644-12, del 28 de febrero de 2013; la No C1441-12, del 1 de febrero de 2013; la $\mathrm{N}^{\circ} \mathrm{C} 1438-12$, del 4 de enero de 2013 y la No C359-12, del 11 del julio de 2012. 
el particular debe soportar el esfuerzo en aras del acceso a la información pública (limitándonos a una información puntual: los datos de carácter personal del tercero) dentro del marco de aplicación de la "Ley de transparencia", se encuentra restringida en la actual estructura doctrinal y jurisprudencial nacional a los siguientes tópicos: en primer lugar, al reconocimiento del deber del Estado de entregar la información; en segundo término, al tratamiento de un tipo de información especialmente resguardada, representada por los datos personales, desde la óptica de la transparencia y, en tercer lugar, a las decisiones de amparo del Consejo para la Transparencia y las sentencias proferidas por las altas instancias del poder judicial en las cuales son tratados los enunciados datos personales. El estudio de los tópicos anteriores, proporciona un punto de partida en el logro de la respuesta al interrogante planteado, situación que tiende a ser más relevante, máxime cuando las propuestas legislativas que podrían dar una mayor orientación sobre esta materia, no se han concretado normativamente.

$3^{\circ}$ La jurisprudencia del Consejo para la Transparencia, observa una clara tendencia a favor del acceso a la información pública por sobre la reserva o secreto de los datos personales. Sin embargo, en algunos casos la opinión de otras altas instancias del poder judicial (como es el caso del Tribunal Constitucional y las Cortes de Apelaciones) ha sido contraria a los argumentos propuestos por el órgano encargado de la transparencia. La incertidumbre que puede generar esa falta de acuerdo, y ante la necesidad de lograr un equilibrio entre la información pública y su acceso (como herramientas de control social del poder en un Estado de derecho), y el resguardo de los datos de carácter personal, sugiere la necesidad de explorar el tratamiento de este tema dentro de algunas experiencias más avanzadas en el ámbito del derecho comparado, como es el caso de México y su Instituto Federal de Acceso a la Información y Protección de Datos IFAI, y el caso del Reino Unido con la Oficina del Comisionado de Información (Information Commissioner's Office).

\section{BIBLIOGRAFÍA}

Aldunate Lizana, Eduardo, Derechos fundamentales (Santiago, Legal Publishing, 2008).

Anguita Ramírez, Pedro, La protección de datos personales y el derecho a la vida privada. Régimen jurídico, jurisprudencia y Derecho comparado (Santiago, Editorial Jurídica de Chile, 2007).

Biblioteca del Congreso Nacional de Chile, Historia de la Ley $N^{\circ} 20.285$ sobre Acceso a la información pública (Santiago, 2008).

CANALES GiL, Álvaro, La protección de datos personales como derecho fundamental, en Anuario Derecho Informático (Montevideo, Fundación de Cultura Universitaria, 2004). 
Diseño de un modelo organizacional del Consejo para la Transparencia en su nueva función de protección de datos personales (Santiago, Centro de Sistemas Públicos, Departamento de Ingeniería Industrial de la Universidad de Chile, 2010).

Boletín Jurídico de la Comisión de Probidad y Transparencia, Secretaria General de la Presidencia, 3 [visible en Internet: http://www.probidadytransparencia.gob.cl/ assets/files/documentos/boletines/juridico/Boletin_Juridico_3.html].

Consejo para la Transparencia entrega decisión en caso sobre correos electrónicos de ministro Larroulet, 4 de abril del 2012 [visible en Internet: http://www.consejotransparencia. $\mathrm{cl} /$ consejo-para-la-transparencia-entrega-decision-en-caso-sobre-correos-electronicos-de-ministro larroulet/consejo/2012-04-04/162926.html].

Estrategias emergentes para el desarrollo de la protección de datos en Chile del Consejo para la Transparencia [visible en Internet: http://www.consejotransparencia.cl/ prontus_consejo/site/artic/20091214/pags/20091214173541.html].

La armonización entre las leyes de transparencia y los estándares internacionales de protección y datospersonales, ponencia dictada por el Consejo para la Transparencia, el $2 \mathrm{de}$ junio del 2010 dentro del Seminario regional de protección de datos, Montevideo.

Protección de datos personales (Santiago, Consejo para la Transparencia, 2011).

Recomendaciones del Consejo para la Transparencia sobre protección de datos personales por parte de los órganos de la Administración de Estado, en Diario Oficial de 14 de Septiembre del 2011.

Delpiazzo, Carlos, $A$ la búsqueda del equilibrio entre privacidad y acceso [visible en Internet: http://www.fder.edu.uy/contenido/pdf/9jornadas_idi.pdf].

GREgorio, Carlos, Los nombres de las partes en los documentos judiciales: vías de acceso a la información, publicidad, y protección de la intimidad (Buenos Aires, Instituto de Investigaciones para la Justicia, 2005).

Jijena Leiva, Renato, Tratamiento de datospersonales al interior de la Administración del Estado como restricción a la Ley 20.285 sobre Transparencia y acceso a la información de los Servicios Públicos, informe en Derecho elaborado a petición del Consejo para la Transparencia en diciembre del 2009 , texto no publicado.

Manual de transparencia y probidad de la Administración del Estado (Santiago, Ministerio Secretaría General de la Presidencia Dirección Nacional del Servicio Civil, 2009).

Pierini, Alicia - Lorences, Valentín, Derecho de acceso a la información (Buenos Aires, Editorial Universidad, 1999).

Piñar Mañas, José Luis, Seguridad, transparencia y protección de datos: El futuro de un necesario e incierto equilibrio (Madrid, Fundación Alternativas, 2009).

Quiroga Laviè, Humberto, Habeas data (Buenos Aires, Zavalia, 2001).

Rajevic Mosler, Enrique, Protección de datos y transparencia en la administración pública chilena: Inevitable y deseable ponderación, ponencia dictada en el 26 de noviembre del 2010 en el taller "Chile y la protección de datos personales", publicada en diciembre del 2010 por la Corporación Expansiva. 